\title{
Electrical Properties of PZT Under High-Pressure Stress Pulse Effects of Loading Frequency and Circuit Load
}

\section{Ruizhi Wang}

Nanjing University of Science and Technology

enling tang ( $\nabla$ tangenling@126.com )

Shenyang Ligong University

\section{Guolai Yang}

Nanjing University of Science and Technology

\section{Yafei Han}

Shenyang Ligong University

\section{Chuang Chen}

Shenyang Ligong University

\section{Mengzhou Chang}

Shenyang Ligong University

\section{Kai Guo}

Shenyang Ligong University

\section{Liping He}

Shenyang Ligong University

\section{Research Article}

Keywords: High-pressure stress pulse, PZT, Load impedance, Electrical output performance

Posted Date: June 12th, 2021

DOl: https://doi.org/10.21203/rs.3.rs-607258/v1

License: (1) (1) This work is licensed under a Creative Commons Attribution 4.0 International License. Read Full License

Version of Record: A version of this preprint was published at Ceramics International on October 1st, 2021. See the published version at https://doi.org/10.1016/j.ceramint.2021.10.023. 


\title{
Electrical properties of PZT under high-pressure stress pulse:
}

\section{effects of loading frequency and circuit load}

\author{
Ruizhi Wang ${ }^{a}$, Enling Tang ${ }^{a, b^{*}}$, Guolai Yang ${ }^{a *}$, Yafei Han ${ }^{b}$,Chuang Chen ${ }^{b}$, Mengzhou Chang ${ }^{b}$, Kai Guo $^{b}$ Liping He $^{b}$ \\ ${ }^{a}$ School of Mechanical Engineering, Nanjing University of Science and Technology, Nanjing 210094, China; \\ ${ }^{b}$ Key Laboratory of Transient Physical Mechanics and Energy Conversion Materials of Liaoning Province, Shenyang Ligong University, \\ Shenyang, 110159, China \\ *Corresponding author. E-mail addresses:tangenling@126.com (E. Tang); yyanggl@njust.edu.cn (G. Yang)
}

\begin{abstract}
The research on the discharge characteristics of PZT under conventional applications has made good progress. In theory, the piezoelectric equation can be used to describe the relationship between stress and electrical output. However, existing studies have shown that the relationship becomes nonlinear under high-pressure stress pulses. To study the effect of loading frequency and circuit load on the electrical output performance of PZT under high-pressure stress pulse, the experiment was carried out based on the split Hopkinson pressure bar and a dynamic \& static universal test machine. The effects of different circuits load on the output voltage under high-frequency and low-frequency high-pressure stress pulses are analyzed. Both theory and experiments prove that the critical open-circuit measurement resistance $\left(R_{\text {critial }}\right)$ of PZT decreases with the load frequency. The output voltage is positively correlated with the load resistance when the load resistance is less than $R_{\text {critial. }}$. It is confirmed by loading different circuits (diodes are added in different positions) that reverse positive charge appears at the negative pole of the material during the stress unloading stage. PZT have the maximum dischargeable strain $\varepsilon_{E M}$ under the high-pressure stress pulses. PZT no longer generates induced charges when the strain is greater than $\varepsilon_{E M}$. When constant strain rate loading makes PZT completely release energy, its open-circuit output voltage is proportional to the strain rate.
\end{abstract}

Keywords: High-pressure stress pulse; PZT; Load impedance; Electrical output performance

\section{Introduction}

When ferroelectric materials have an asymmetric phase structure below the Curie temperature, they have spontaneous polarization. Its remarkable feature is that the direction of spontaneous polarization can be changed by an external electric field. At present, there are more than 700 kinds of ferroelectrics that have been discovered, and the most studied materials are oxides and ferroelectric polymers [1-4]. Among them, $\mathrm{PbZrTiO}_{3}$ (PZT)-based ferroelectric shows excellent piezoelectric properties due to the existence of a morphotropic phase boundary (MPB) [5-8]. PZT is widely used in various sensors, actuators and pulse power supply due to its good electromechanical coupling characteristics. In these applications, the electric energy is stored in PZT during the initial polarization process and released to the electric load by external stress loading. Based on the special force-electric response relationship of piezoelectric ceramics, it is usually subjected to stress pulses during the application, such as high-frequency resonance excitation, vibration and shock. Especially in the more demanding applications in the defense industry, PZT may be subjected to high-pressure stress pulses such as overload stress [9,10], shock waves [11-14] and detonation waves 
$[15,16]$. The electrical output properties of PZT under high-pressure stress pulses are used to realize the unique functions of devices, such as pulse igniter, explosive transducer and piezoelectric power supply [17-19].

Pulse igniter refers to a missile-borne energy device that transfers the output energy of PZT to ignite the load initiating explosive device. Its structure generally includes mass block, PZT, electro-explosive device (EED) and wire, as shown in Fig.1 (a). The pulse igniter is placed in the missile, and the ignition mode can be selected through the dowel, such as launch ignition mode or impact ignition mode. When the launch ignition mode is selected, the mass block I is fixed, the overload force of mass block II was used to act on the PZT during the missile firing process, and the electric energy output from the ceramics is used to activate the EED. On the contrary, when the impact ignition mode is selected, the mass block II is fixed, and the EED is activated by the overload force generated by mass block I during the impact between the missile and the target. How to control accurately the output energy of PZT under pulse stress is the key problem to solve the reliability of pulse igniter. Studies have shown that the output energy of PZT is related to the impedance of the load [20], and a reasonable adjustment of the matching relationship between the load impedance and PZT is conducive to improving its energy conversion rate. Su et al. [21] shows that the critical open-circuit measurement resistance of PZT is related to the loading frequency. Tang et al. [22] studied the electrical output performance of PZT-5H under different stress pulse frequencies, and the results showed that the output voltage duration of PZT was proportional to the action time of the loading wave. The longer the stress pulse duration was, the greater the output energy was. Therefore, the influence of loading frequency and load impedance must be considered when the output energy of the piezoelectric devices was evaluated.
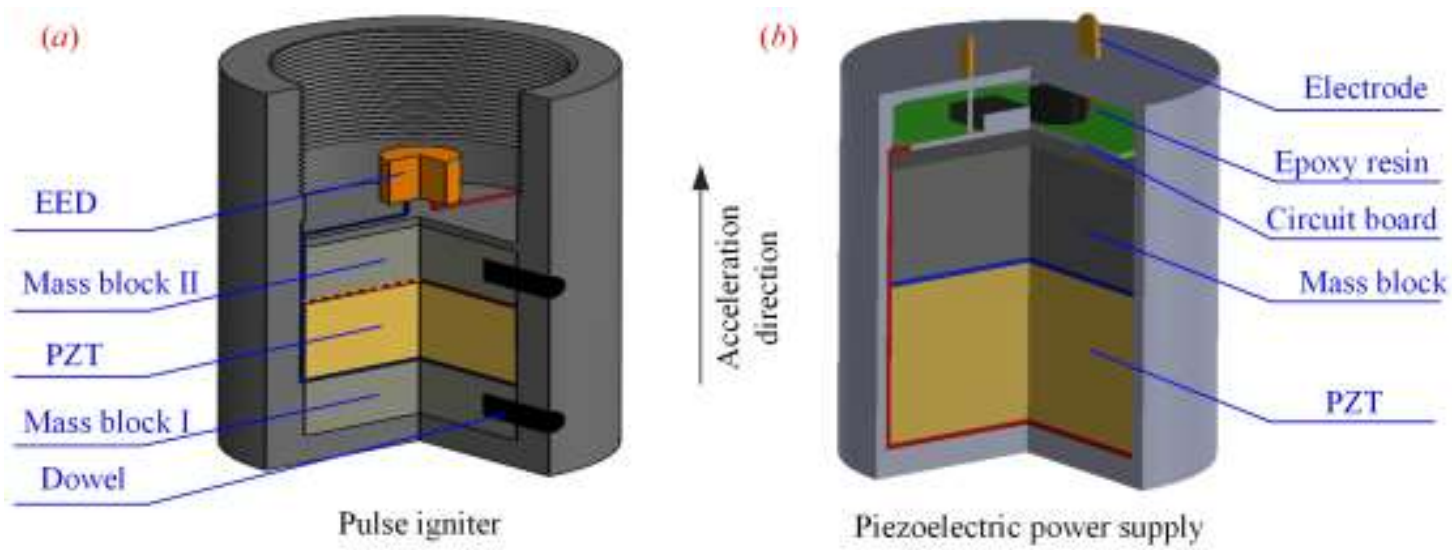

Fig.1 Typical piezoelectric devices for ammunition. (a) pulse igniter; $(b)$ piezoelectric power supply.

In addition, another typical application of PZT in missile-borne devices is the piezoelectric power supply. Its typical structure is shown in Fig.1 (b). The overload force provided by the mass block is used to compress the PZT, and the output energy is 
stored in the capacitor through the energy storage circuit. The stored energy may be used to activate EEP or provide energy for other micro-electro-mechanical systems (MEMS). For traditional energy harvesting devices, only when the excitation frequency is close to the resonant frequency of the generator can it work effectively. Therefore, compared with other excitation methods, the research on vibration is more common $[23,24]$, and its compactness and circuit integrability have been proved to be an ideal energy source for MEMS. In recent years, the research on related energy harvesting circuits has also made great progress [25-29]. The difference lies in that PZT is usually subjected to high-pressure stress pulses when they are used in missile-borne devices. PZT may have a depolarization effect under the high-stress field and releasing a large amount of charge at some moment [30]. Previous work has studied the nonlinear force-electricity relationship of PZT under high-pressure stress pulses and established a dynamic force-electricity response model based on the strain rate effect [12,31]. However, to develop smart piezoelectric devices efficiently and reliably, the relationship between loading frequency, circuit load and output energy are still the common concern in the application research of piezoelectric devices based on high-pressure excitation.

In this paper, based on the improved spit Hopkinson pressure bar system (SHPB) and dynamic \& static universal test machine, the electrical output performance measurement experiment of PZT under high-pressure stress pulse is carried out. The influence of load resistance and energy storage circuit on the electrical output performance under high-frequency stress pulse is studied, and the output voltage and energy of PZT under different stress pulse frequencies are analyzed. These studies will lay a foundation for the application of PZT under extreme stress pulses.

\section{Experimental methods}

\subsection{Loading and measuring methods}

Compression experiments were conducted with a dynamic \& static universal test machine and an SHPB as the loading ways to obtain the mechanical and electrical properties of PZT under different loading frequencies and circuit loads. The experiments were conducted in the Key Laboratory of Transient Physical Mechanics and Energy Conversion Materials of Liaoning Province, China. Fig.2 shows the experimental loading and testing system diagram. In the low-frequency loading experiment, as shown in Fig.2 (a), the size of the sample is $\Phi 14 \times 2 \mathrm{~mm}^{2}$, the maximum loading force of the test machine is $100 \mathrm{kN}$, and the loading rate range is from 0.01 to $500 \mathrm{~mm} / \mathrm{min}$. 


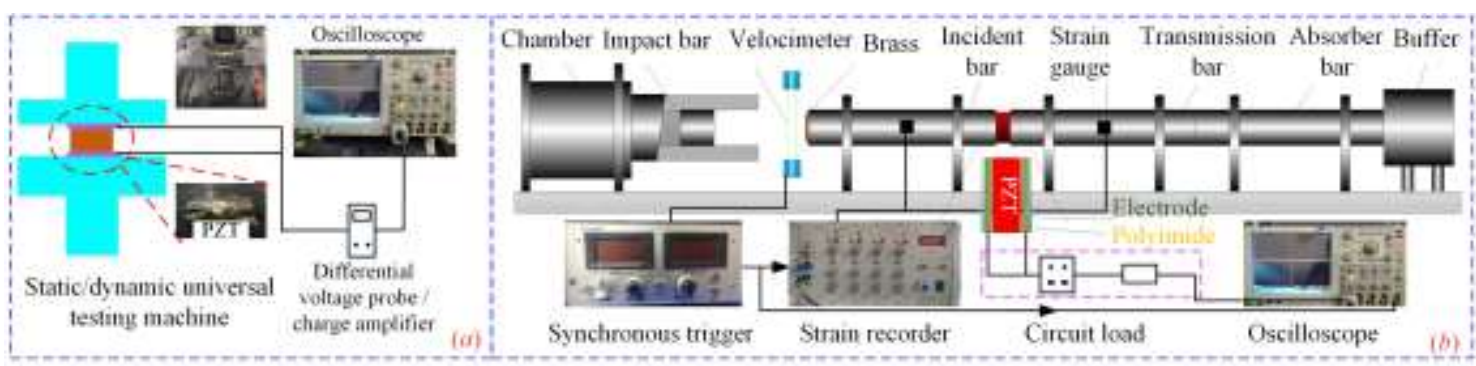

Fig.2 Experimental loading and testing system. (a) low-frequency stress pulse loading; $(b)$ high-frequency stress pulse loading.

In the high-frequency loading experiment, the experimental loading system is mainly composed of the impact bar, incident bar, transmitted bar and absorbers with diameters of $16 \mathrm{~mm}$, and the material of the bars is aluminum alloy. The lengths of the impact bar are $100 \mathrm{~mm}, 200 \mathrm{~mm}$ and $300 \mathrm{~mm}$, respectively, and the lengths of the incident and transmitted bars are both 1,200 mm. Because PZTs are brittle materials with small failure strains, it is difficult to ensure a short loading duration and uniform internal stress in the tested samples. Therefore, the sample size must be strictly controlled to delay the rise time of the load waveform as much as possible to achieve stress uniformity within the sample. Therefore, the brass pulse shaper is connected to the front of the incident bar. Polyimide is used as the insulating material among the sample, incident bar and the transmitted bar. The thickness of the polyimide is set to $0.005 \mathrm{~mm}$ and reduce the effects of the insulators on the propagation of the stress waves. An aluminum film with a thickness of $0.1 \mathrm{~mm}$ is used as the sample electrode to minimize the interference from impedance mismatch, and the electrode is connected to the PZT-5H ceramic by using conductive glue. Vacuum silicone grease is applied to each contact surface and reduces friction [12].

The transient electrical measurement system consists of a synchronous trigger, strain recorder, circuit load and oscilloscope. The strain recorder with the strain gauges is used to measure the stress and strain signals of the samples under impact. The circuit load is combined with a voltage/current probe to measure the electrical signals. All the signals are recorded by the oscilloscope, and the photoelectric signals produced by the laser velocimeter are used as the input signals of the synchronous trigger. The model of the high voltage differential probe is Tektronix THDP0200, and the maximum measurement voltage and input impedance are $\pm 1,500 \mathrm{~V}$ and $10 \mathrm{M} \Omega$, respectively.

\subsection{Piezoelectric materials}

$\mathrm{Pb}_{1.0}\left[\mathrm{Zr}_{0.49} \mathrm{Ti}_{0.46}\left(\mathrm{Nb}_{0.25} \mathrm{Sb}_{0.75}\right)_{0.05}\right]_{1.0} \mathrm{O}_{3}(\mathrm{PZT}-5 \mathrm{H})$ is a flexible piezoelectric ceramic with a high piezoelectric coefficient, high electromechanical coupling coefficient, low mechanical quality factor and good aging resistance. It is widely used in various sensors and power supplies. The PZT-5H produced by Yuhai Electronic Materials Co., Ltd. , its diameters and thicknesses were $14 \mathrm{~mm}$ and $2 \mathrm{~mm}$, respectively, was used as the sample 
to carry out loading experiments under different conditions. The surfaces of the sample are ground and profiled after sintering and plated with silver electrodes. The polarization intensity of the material is $34 \mu \mathrm{C} / \mathrm{cm}^{2}$, and the coercive electric field is 8 $\mathrm{kV} / \mathrm{cm}$. An electric field with twice as strong as the coercive field is applied to pre-polarize the material along the thickness direction. The parameters of the sample, determined by the merchant, are shown in Table 1.

Table 1 Basic performance parameters of the PZT-5H piezoelectric ceramic

\begin{tabular}{cc}
\hline Parameter & Value \\
\hline Density, $\rho / \mathrm{kg} \cdot \mathrm{m}^{-3}$ & 7500 \\
Curie point $/{ }^{\circ} \mathrm{C}$ & 230 \\
Piezoelectric constant, $d_{33} / \times 10^{-3} \mathrm{Vm} \cdot \mathrm{N}^{-1}$ & 620 \\
Relative permittivity, $\varepsilon_{\mathrm{r}} /-$ & 3200 \\
Young's modulus $/ 10^{9} \mathrm{~N} \cdot \mathrm{m}^{2}$ & 56 \\
Poisson's ratio & 0.36 \\
Elastic compliance coefficient, $S_{33}^{D} / \times 10^{-12} \mathrm{~m}^{2} \cdot \mathrm{N}^{-1}$ & 7.6 \\
\hline
\end{tabular}

\section{Results and discussion}

\subsection{Electrical output characteristics of PZT under high-frequency stress pulse}

\subsubsection{The influence of load resistance}

The aluminum bar with a length of $100 \mathrm{~mm}$ is used as impact bar at the speeds of $2.6 \mathrm{~m} / \mathrm{s}, 3.6 \mathrm{~m} / \mathrm{s}$ and $4.8 \mathrm{~m} / \mathrm{s}$, respectively. Fig. 3 (a) shows the stress time history at different speeds. When the load resistance is $1 \mathrm{M} \Omega$, the output voltage of PZT is shown in Fig.3 (b).
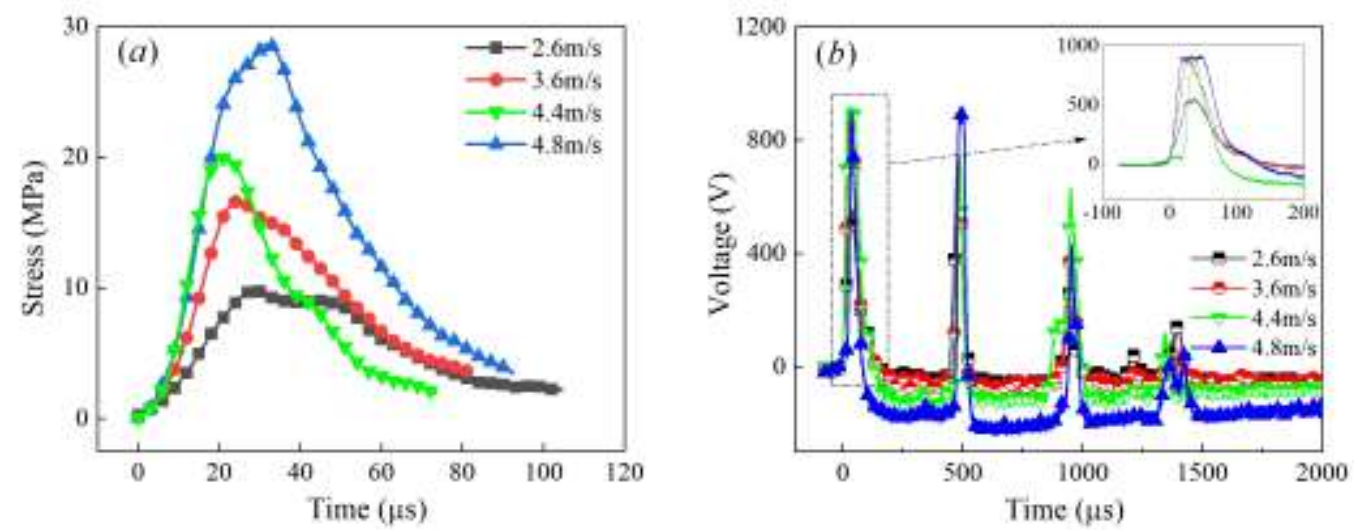

Fig.3 The output voltage of PZT-5H under different impact speeds (load resistance=1M $\Omega$ ). (a) stress time history; $(b)$ voltage time history.

The material will bear the impact load many times under the loading mode of SHPB. To study the relationship between the output voltage and the loading stress, only the head wave effect is considered. It can be seen from Fig. 3 that the maximum stress $\sigma_{\max }$ of PZT is about $10 \mathrm{MPa}$ when the impact speed is $2.6 \mathrm{~m} / \mathrm{s}$, and the maximum voltage $U_{\max }$ at both ends of the load resistance is $543 \mathrm{~V}$. The larger the impact speed is, the larger $U_{\max }$ is. When the maximum stress $\left(\sigma_{\max }\right)$ is $20 \mathrm{MPa}$, the maximum output voltage $\left(U_{\max }\right)$ is $910 \mathrm{~V}$. However, when $\sigma_{\max }$ continues to increase up to $26 \mathrm{MPa}, U_{\max }$ 
still remains $910 \mathrm{~V}$. It can be seen that for the PZT-5H with a thickness of $2 \mathrm{~mm}$, when the loading stress is greater than $20 \mathrm{MPa}$, the maximum output voltage no longer increases, but remains stable at $910 \mathrm{~V}$. The strain range of the sample under different strain rates is between $0.4 \%$ and $1 \%$ when the $\sigma_{\max }$ is $20 \mathrm{MPa}$. There are no more induced charge when the compressive strain of the material is greater than a certain threshold. The reason can be explained by the internal field theory in the literature [31]. Moreover, the literature [32] shows that $U_{\max }$ of PZT-5H with a thickness of $5 \mathrm{~mm}$ under a stress pulse is about $1,200 \mathrm{~V}$, indicating that $U_{\max }$ is related to the thickness of PZT.
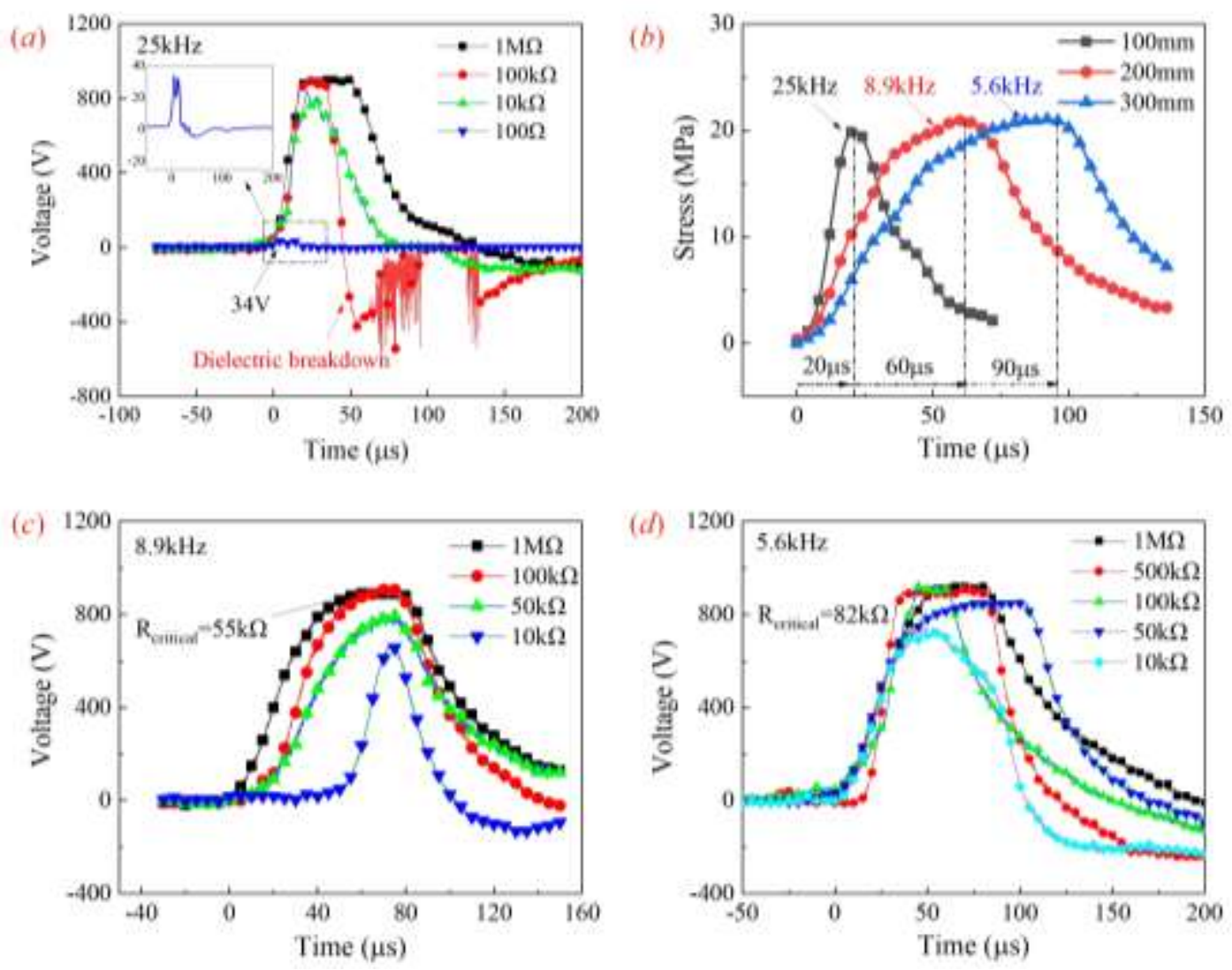

Fig.4 The influence of loading frequency and load resistance on output voltage under high-frequency stress pulse $(4.8 \mathrm{~m} / \mathrm{s})$. (a) length of the impact bar is $100 \mathrm{~mm}$; $(b)$ stress time history curves produced by different impact bars; $(c)$ length of the impact bar is $200 \mathrm{~mm}$; $(d)$ length of the impact bar is 300 $\mathrm{mm}$

The speed of the impact bar is controlled at about $4.8 \mathrm{~m} / \mathrm{s}$, and the experiments with different load resistances are conducted on the same kind of PZT-5H. The voltage across the resistance is shown in Fig.4 (a), indicating that $U_{\max }$ increases from $34 \mathrm{~V}$ to $830 \mathrm{~V}$ when the load resistance $R_{\text {load }}$ increases from $100 \Omega$ to $10 \mathrm{k} \Omega$, and $U_{\max }$ become $910 \mathrm{~V}$ when $R_{\text {load }}$ is $100 \mathrm{k} \Omega$. Then it remains unchanged when $R_{\text {load }}$ continues to increase. Different load resistances have a greater effect on the output voltage of the piezoelectric ceramics, and the biggest $U_{\max }$ is 20 times the smallest one. According to Su's research conclusions [21], as a general standard for voltage measurement of piezoelectric devices, the load resistance must be greater than the critical resistance when the ideal 
open-circuit measurement conditions are met. The critical resistance can be expressed as

$$
R_{\text {critical }}=\frac{f t_{\delta}}{C f \ln \left[1 /\left(1-\delta / \bar{\varepsilon}_{\text {aver }}\right)\right]}
$$

wherein, $f$ is the frequency of the load; $\delta$ is the ratio between the lost voltage at the conditions of $t=t_{\delta}$ and the maximum open-circuit voltage, which stands for the error of voltage measurement for open-circuit; $f t_{\delta}$ is dimensionless time; $C$ is the effective capacitance of the device measured; $\bar{\varepsilon}_{\text {aver }}$ is the average value of the dimensionless strain. The load resistance must be larger than $R_{\text {critical }}$ to ensure the error of voltage measurement for open-circuit $\delta<1 \%$.

The interatomic spacing of piezoelectric ceramics changes when the material is compressed, which in turn causes the effective capacitance to change. The dielectric spectrum of PZT-5H under different static pressure is measured by LCR digital bridge as shown in Fig.5, indicating that the dielectric constant increases from 3200 to 3500 under the interaction of stress. However, the dielectric constant does not change regularly with the increase or decrease of stress, and the effect of stress on PZT capacitance is limited. For the piezoelectric materials used in experiment, the capacitance varies from 2.2 to $2.4 \mathrm{nF}$ under different stresses, but the capacitance difference between different materials caused by the manufacturing process ranges from 2.1 to $2.4 \mathrm{nF}$. Therefore, the influence of stress loading on the capacitance can be ignored in the calculation, and $C=2.2 \mathrm{nF}$ is selected in this paper.

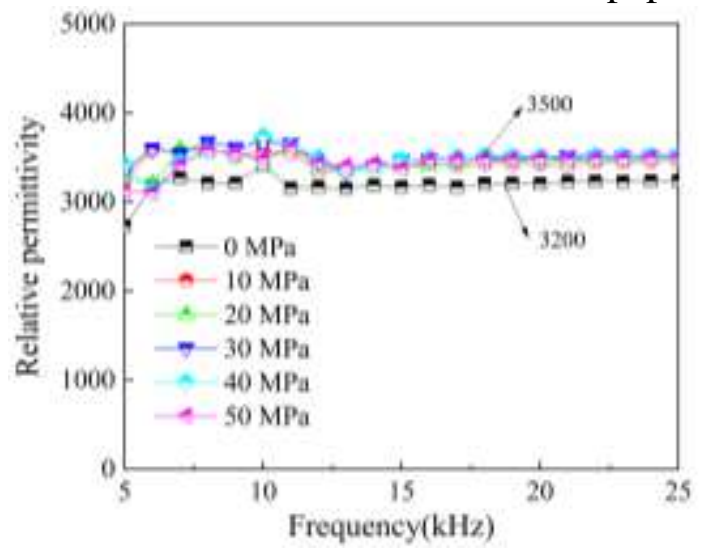

Fig.5 Dielectric spectrum of PZT under different stress

According to the stress time history curve shown in Fig.3 (a), the stress loading frequency is about $25 \mathrm{kHz}$ when the length of the impact bar is $100 \mathrm{~mm}$. According to Eq. (1), $R_{\text {critical }}$ is $18 \mathrm{k} \Omega$ at this loading frequency. The experimental results have shown that the open-circuit condition is satisfied when $R_{\text {load }}$ is $100 \mathrm{k} \Omega$ or $1 \mathrm{M} \Omega$, as shown in Fig.4 (a). At this condition, the discharge voltage of the piezoelectric ceramics is relatively stable, and the peak voltage no longer increases with the variable resistance. In order to further verify the reliability of the open-circuit measurement theory under impact loading, the experiments with different lengths of impact bars (200 mm, $300 \mathrm{~mm})$ at the near speed (about $4.8 \mathrm{~m} / \mathrm{s}$ ) were carried out. Fig.4 $(b)$ shows the stress time 
history curves of the samples under different impact conditions, which shows that the duration of the stress pulse formed by different impact bars is different, and the corresponding loading frequencies of the three kinds of impact bars are $25 \mathrm{kHz}, 8.9 \mathrm{kHz}$ and $5.6 \mathrm{kHz}$, respectively. According to Eq. (1), the corresponding $R_{\text {critical }}$ of the loading resistances are $18 \mathrm{k} \Omega, 55 \mathrm{k} \Omega$ and $82 \mathrm{k} \Omega$, respectively. Figs. $4(c)$ and $(d)$ show the influence of different load resistance on the output voltage under the corresponding frequency.

As can be seen from Fig.4 (c), the output voltage is the same when $R_{\text {load }}$ is $100 \mathrm{k} \Omega$ or $1 \mathrm{M} \Omega$ and the loading frequency of $8.9 \mathrm{kHz}$, which meets the open-circuit measurement condition. However, in Fig.4 (d), although $R_{\text {load }}=100 \mathrm{k} \Omega$ has met the theoretical open-circuit measurement condition when the loading frequency is $5.6 \mathrm{kHz}$, the duration of the output voltage is short, which is different from $R_{\text {load }}=1 \mathrm{M} \Omega$ and cannot fully meet the open-circuit measurement condition. However the open-circuit measurement condition is fully satisfied when $R_{\text {load }}$ is increased to $500 \mathrm{k} \Omega$. Therefore, in the engineering measurement, in order to fully meet the ideal open-circuit measurement conditions, the load resistance should be 1.5 times as large as $R_{\text {critical }}$.

The experimental results show that the output voltage of PZT-5H is relatively stable, which is about $900 \mathrm{~V}$, when the ideal open-circuit test condition is satisfied; and $U_{\max }$ increases with the load resistance when the condition $R_{\text {load }}$ is not larger than $R_{\text {critical }}$. The research on the electrical output performance of PZT loaded with lower resistance (e.g. $5 \Omega$ or $10 \Omega$ ) under high-frequency stress pulses can be referred to $[10,12,20,32]$. The conclusion is that the output voltage of PZT is positively correlated with the load resistance, and the output current is negatively correlated with the load resistance. When PZT are used in pulse igniter, the energy conversion efficiency can be improved by choosing suitable load resistance.

In addition, the negative value of the open-circuit output voltage of the piezoelectric ceramics at the unloading stage is particularly noteworthy under the impact condition, as shown in Fig.6 (a). After the first stress pulse, the open-circuit voltage of PZT is stabilized at $-200 \mathrm{~V}$ instead of zero volt. It can be seen from Fig.6 (b) that there is a residual strain in the piezoelectric material when the stress is unloaded. The charge release process of PZT under stress loading and unloading can be represented by the model shown in Fig.6 (c): after polarization, there are electric dipoles in the same direction inside the PZT, forming residual polarization in the macroscopic view. At the same time, opposite charge is induced on the surface of the material. The electric dipole turns and the induced charge adsorbed on its surface is released when the stress is loading. The electric field is depolarized under open-circuit, and the measured voltage is positive. However the sample is subjected to a reverse tensile wave when the stress is unloading, and its deformation has a hysteresis effect on the tensile wave (due to its 
ferroelasticity). When the tensile wave is applied, the sample is remained in a compression state and the dipole is more easily turned. In other words, more reverse induction charges are generated under the same stress, so the voltage is stabilized to a negative value. Then, the voltage increases again based on the negative voltage when the stress pulse continues to increase. Finally, the voltage slowly returns to zero with the gradual recovery of strain when the loading is stopped. The theory will be further verified in the next section when PZT is generated a reverse positive charge under the unloading wave.
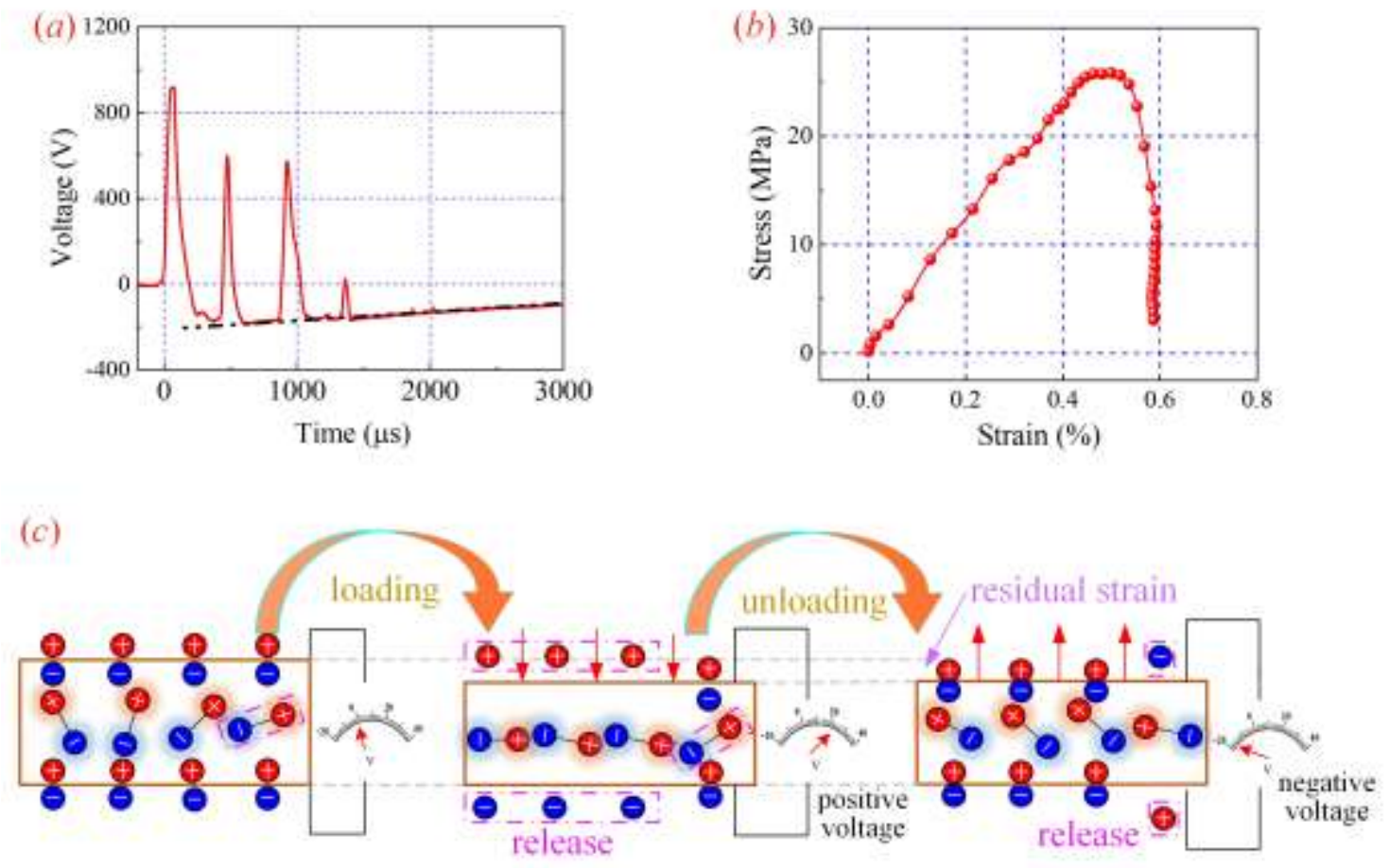

Fig.6 Typical open-circuit voltage of PZT under impact. (a) output voltage with a negative value; $(b)$ residual strain after stress unloading; $(c)$ open-circuit discharge model.

\subsubsection{The influence of energy storage circuit}

Another use of PZT in ammunition is piezoelectric power supply, which means that the launching overload or other flight overload acting on piezoelectric materials is utilized, and capacitors are used to collect the electric energy generated by the piezoelectric materials, so as to supply power for other missile-borne equipment. The energy conversion efficiency improved is the research focus of the piezoelectric power supply. The SHPB experiments are used to analyze the influence of the energy storage circuit on the electrical output performance of PZT. In experiments, the impact speeds are all $3 \mathrm{~m} / \mathrm{s}$, the diameter and thickness of the ceramic are $16 \mathrm{~mm}$ and $2 \mathrm{~mm}$, respectively, and the capacitance is $3.2 \mathrm{nF}$. In experiments, four kinds of energy storage circuits are used, as shown in Fig.7. The capacity of energy storage capacitor $\mathrm{C}_{2}$ is 2.6 nF. Fig.8 (a) shows the electrical output results of the four types of energy storage circuits. 
It can be seen from the experimental results that the output voltage is synchronized with the loading stress in the form of the pulse in the C-C circuit mode. If the PZT is regarded as the capacitor $\mathrm{C}_{1}$, the circuit can be equivalent to two capacitors charging and discharge each other, and its initial electric energy depends on the polarization of the material. The capacitors $\mathrm{C}_{1}$ and $\mathrm{C}_{2}$ are charged by piezoelectric charge at the same time. The amount of charge on the two capacitors is equal when the voltage is balanced. The voltage measured by the voltmeter is lower than that measured by open-circuit due to the shunt effect of $\mathrm{C}_{2}$ during charging. During the process of stress unloading, the opposite charge on $\mathrm{C}_{1}$ is counteracted by $\mathrm{C}_{2}$ and resulting in a smaller negative voltage. Moreover, the output voltage of the material under the second stress pulse is obviously smaller than that of the third stress pulse although the peak value of the second stress pulse is larger than that of the third.

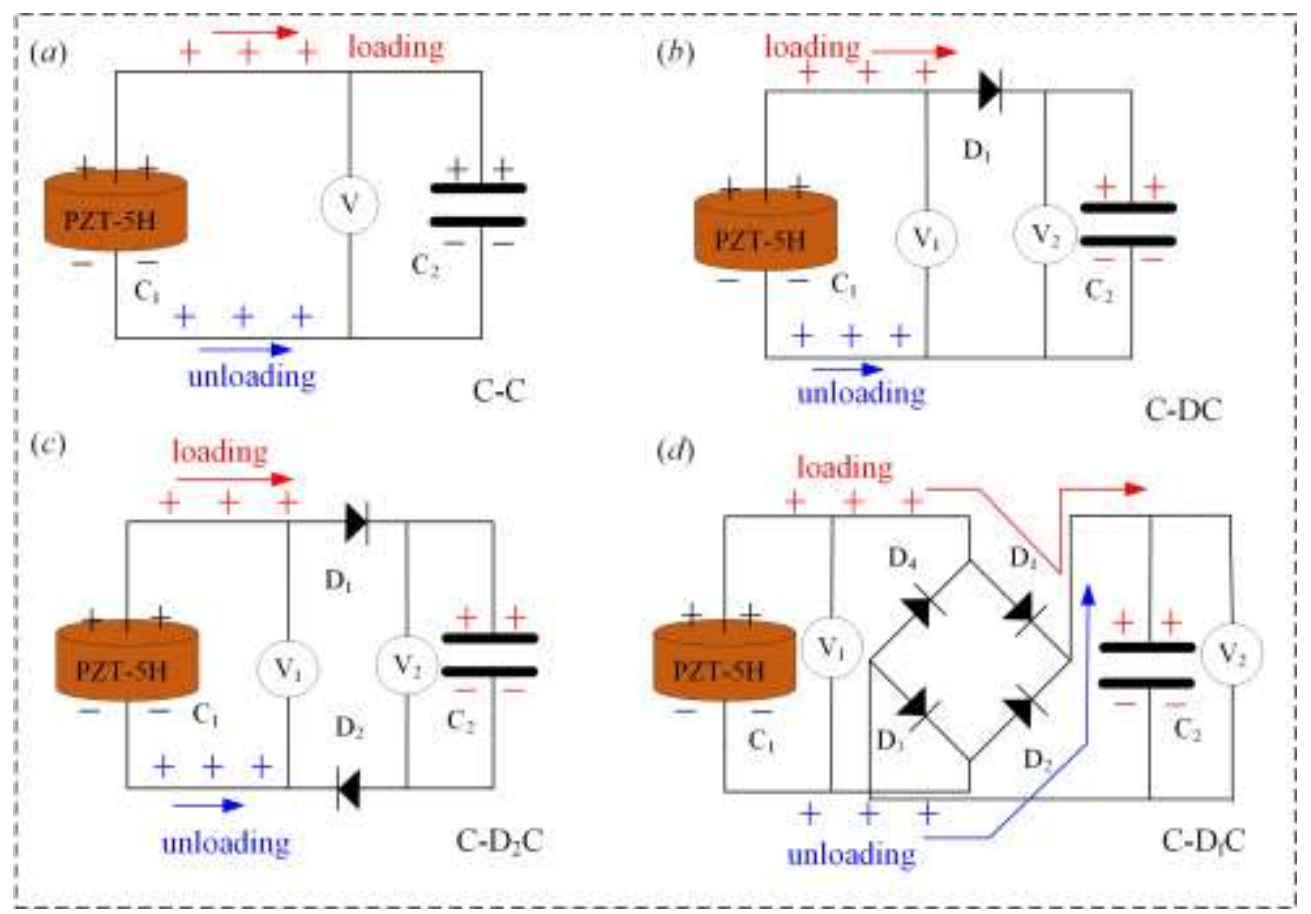

Fig.7 Four types of energy storage circuits. (a) load capacitance only (C-C); (b) load capacitance and connect a diode in series with the anode (C-DC); (c) load capacitance and connect two diodes in positive and negative poles series in opposite directions $\left(C-\mathrm{D}_{2} \mathrm{C}\right) ;(d)$ load capacitance and full bridge rectifier module $\left(\mathrm{C}-\mathrm{D}_{\mathrm{r}} \mathrm{C}\right)$.

RHRG6020 ultra-fast recovery diode is added in the circuit to avoid the charge leakage from $\mathrm{C}_{2}$ to $\mathrm{C}_{1}$, forming a $\mathrm{C}$-DC circuit. Voltmeter $\mathrm{V}_{1}$ is used to measure the output voltage of the PZT, and $\mathrm{V}_{2}$ is used to measure the voltage at both end of capacitor $\mathrm{C}_{2}$. It can be seen from Fig. 8 that $\mathrm{C}-\mathrm{DC}-\mathrm{V}_{1}$ is still negative in the unloading stage, which indicates that the output voltage of the piezoelectric ceramic is not related to the diode and the subsequent load. Meanwhile, the results confirm the theory that the charge on the energy storage capacitor reversely replenishes the PZT in the unloading stage. On the other hand, C-DC- $\mathrm{V}_{2}$ decreases and then tends to be stable when the stress 
is unloaded. The decreased amplitude is about $280 \mathrm{~V}$, which is equal to the negative voltage of PZT in the unloading stage. Therefore, we speculate that the reverse charge generated by PZT in the unloading stage flows into the negative electrode of $\mathrm{C}_{2}$ through the lower half of the loop, and the reverse positive charge offsets part of the electric energy stored in capacitor $\mathrm{C}_{2}$ at the loading stage. At the same time, the results verify the model shown in Fig.6 (c).
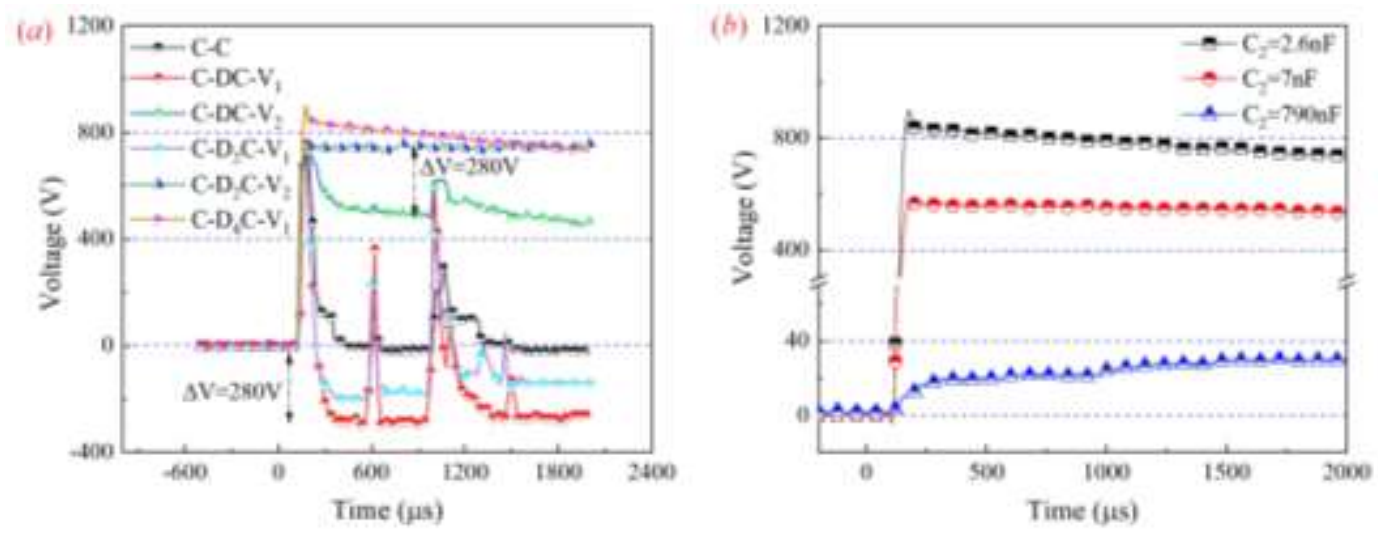

Fig.8 Output voltage time history curves. (a) output voltage of four circuits; (b) energy storage voltage of $\mathrm{C}-\mathrm{D}_{\mathrm{f}} \mathrm{C}$ under different capacitor values of $\mathrm{C}_{2}$.

In order to verify the above conjecture, a reverse diode is added to the negative electrode to prevent the positive charge generated by the reverse from consuming the electric energy on the load capacitor, forming a $\mathrm{C}-\mathrm{D}_{2} \mathrm{C}$ circuit. It can be seen from $\mathrm{C}-\mathrm{D}_{2} \mathrm{C}-\mathrm{V}_{2}$ that $\mathrm{D}_{2}$ in Fig.7 $(\mathrm{c})$ hinders the reverse charge, therefore the voltage of $\mathrm{C}_{2}$ does not decrease with the unloading of stress, and finally stabilizes at $750 \mathrm{~V}$. The experimental results further verify the model in Fig.6 (c).

Furthermore, a GBU810 bridge rectifier module is added to the circuit to improve the energy conversion rate of the piezoelectric power supply, forming the $\mathrm{C}-\mathrm{D}_{\mathrm{f}} \mathrm{C}$ circuit. The DC blocking voltage of GBU810 is $1,000 \mathrm{~V}$ and RMS reverse voltage is $700 \mathrm{~V}$. From the $\mathrm{C}-\mathrm{D}_{\mathrm{f}} \mathrm{C}-\mathrm{V}_{2}$ curve in Fig.8, it can be seen that the output voltage of PZT is relatively stable in this mode, and the maximum voltage is $890 \mathrm{~V}$. Because of the small capacitance of $\mathrm{C}_{2}$, the output energy of PZT-5H reaches $81 \%$ of the total energy of the capacitor, which leads to charge leakage. After changing the capacity of the energy storage capacitor, the charging voltage on $\mathrm{C}_{2}$ is shown in Fig.8 (b). The result show that the voltage is relatively stable when the condition is $C_{2}>C_{1}$ and in the same order of magnitude as $\mathrm{C}_{1}$, and the internal leakage charge is small. But its stable voltage is only $590 \mathrm{~V}$, which is less than the former. However, when the condition is $C_{2}>>C_{1}$, the maximum voltage of the capacitor is only $30 \mathrm{~V}$, and the energy conversion rate is greatly reduced. The experimental results show that the stored energy decreases with the increase of the load capacitance. If the ratio of $C_{2}$ to $C_{1}$ is defined as energy storage capacitance factor $\zeta$, then the energy conversion rate of the energy storage circuit is well when $1 \leqslant \zeta \leqslant 10$. 


\subsubsection{The discharge model}

The mechanical-electrical coupling process can be better understood by a special "sponge" with a water-flow system as shown in Fig.9 [21]. A special "sponge" is connected with two containers, which are connected via a tube, and the water-flow is controlled by a valve. The particularity of the "sponge" is that the water in the container will be additionally absorbed in the rebound process, which corresponds to the negative voltage process in the unloading stage of PZT. The sponge after absorbing water can be regarded as the pre-polarized PZT, and the two containers are equivalent to the capacitance and external load of the piezoelectric ceramics.

In the load resistance mode (as shown in Fig.6 (a)), the resistance is equivalent to the valve controlling the water/current. The valve is not fully closed when the resistance has not reached the open-circuit measurement threshold. In this case, the water/charge passes through the valve/resistor, causing the voltage measured to fall below the ideal open-circuit condition. When the valve is fully closed, the charge will not leak through the resistor, which is equivalent to a completely open-circuit. In the unloading stage, the sponge rebounds and absorbs all the released water/charge, as well as an additional part of the original water/charge in the container.
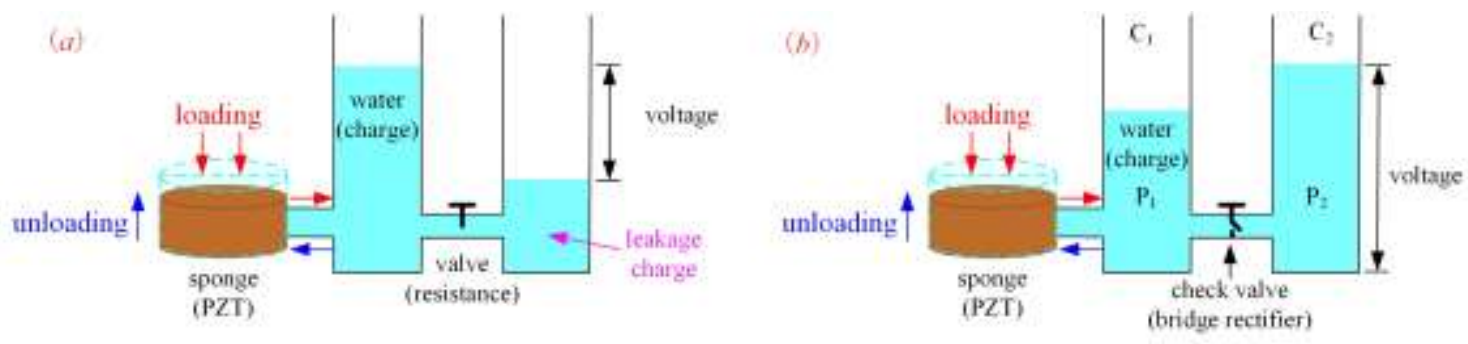

Fig.9 Electromechanical response equivalent model of piezoelectric materials. (a) load resistance; $(b)$ load capacitance.

In the load capacitance mode, as shown in Fig.9 $(b)$, container $\mathrm{C}_{1}$ is equivalent to the capacitance of PZT and $\mathrm{C}_{2}$ is the load capacitance. The two containers are connected through the check valve, which is equivalent to the bridge rectifier. At the loading stage, the water/charge in the sponge is extruded/released, and the water pressure $\left(\mathrm{P}_{1}\right) /$ voltage $\left(V_{1}\right)$ is formed in container $C_{1}$. The water/charge in container $C_{1}$ flows into $C_{2}$ through the check valve/bridge rectifier to form the water pressure $\left(\mathrm{P}_{2}\right) /$ voltage $\left(\mathrm{V}_{2}\right)$. At the unloading stage, the water/charge in container $\mathrm{C}_{1}$ returns to the sponge, and it in container $\mathrm{C}_{2}$ remains stable under the action of the check valve. The value of $\mathrm{V}_{2}$ depends on the diameter of the container $\mathrm{C}_{2}$, i.e. capacitance. With the help of the water flow model, it is easier to understand the mechanical-electrical response of the piezoelectric ceramics under impact. At the same time, the flow model is also applicable in other loading modes. In short, the main characteristic of the mechanical-electrical response of piezoelectric materials under impact load is the negative voltage in the 
unloading stage.

\subsection{Electrical output characteristics of PZT under low-frequency stress pulse}

\subsubsection{Mechanical response}

Uniaxial compression experiments were performed to study the mechanical response and electrical output characteristics of PZT under low-frequency stress pulse loading by a dynamic \& static universal test machine. The sample was clamped between two steel plates and compressed under a constant vertical load in the uniaxial compression experiment. The amplitude and strain rate of the load was adjusted according to the expected loading frequency, and the loading rates were selected as 1 $\mathrm{mm} / \mathrm{min}, 10 \mathrm{~mm} / \mathrm{min}$ and $100 \mathrm{~mm} / \mathrm{min}$, respectively.

Firstly, the mechanical response of the sample was studied when the loading rate was $1 \mathrm{~mm} / \mathrm{min}$. In this case, the strain rate is $0.03 \mathrm{~s}^{-1}$, which can be regarded as quasi-static loading. Based on the experimental results shown in Fig.10, the failure strength of PZT-5H is $437 \mathrm{MPa}$. However, it is found that brittle piezoelectric ceramics will break along the edge and splash around during the loading process. The failure strength calculated from the initial area will not be accurate due to the change of the actual area of the material after cracking. After amplifying the loading signal (Fig.10 (b)), one can see that the sample cracks for the first time when the loading stress is 198 $\mathrm{MPa}$. Therefore, the true fracture strength of PZT-5H is about $200 \mathrm{MPa}$ under quasi-static loading.
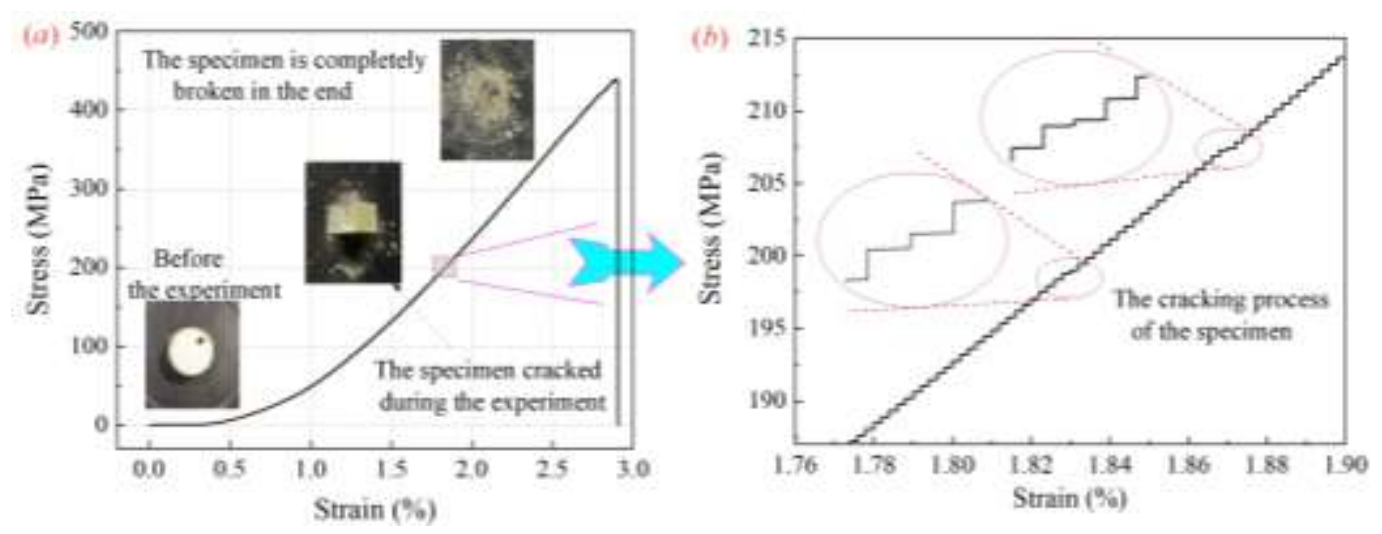

Fig.10 Quasi-static stress-strain curve of PZT-5H (unconstrained). (a) complete curve; (b) local enlarge.

Piezoelectric materials are often circumferentially constrained in engineering applications. In order to be closer to the engineering situation, a rubber tube is used to constrain the material around, and the mechanical response of the sample with the constraint is tested at different loading rates, as shown in Fig.11. It can be seen that there is no splash in the compression process after the restraint is added. When the loading stress exceeds the fracture strength, the sample will fracture along the center. Moreover, the experimental results also show that the fracture strength increases with the increase of the strain rate. 


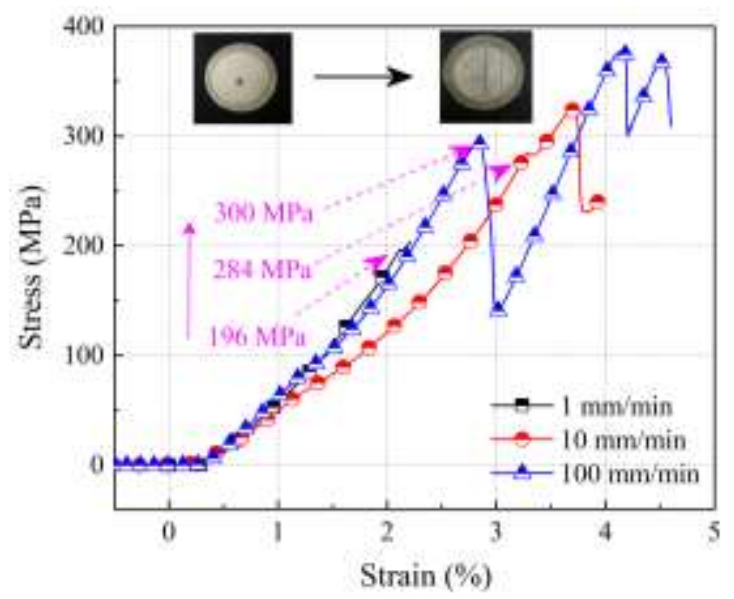

Fig.11 Stress-strain curve of PZT-5H under different strain rates (surrounding constraints)

\subsubsection{Electrical output properties of PZT under low-frequency stress loading}

The discharge characteristics of PZT under low-pressure stress loading obey the quasi-static piezoelectric equation. However, the piezoelectric coefficient will change under high-pressure stress [32]. In addition, the electrical output characteristics of PZT under different loading rates may be different [12]. In order to find out the electromechanical relationship of PZT under high-pressure and low-frequency stress, the open-circuit output voltage of PZT-5H under different loading rates was measured by using a high voltage differential probe, and the results are shown in Fig.12.

The experimental results show that the output voltage of PZT does not always increase with the stress under a constant strain rate. Specifically, the piezoelectric ceramics stop discharge when the strain is greater than a certain threshold, although the stress is still increasing. This phenomenon is consistent with that of high-frequency stress pulse (Fig.3). If this strain threshold is called the maximum dischargeable strain $\varepsilon_{E M}$, it can be seen from Figs. $12(a),(b)$ and $(c)$ that different samples have different $\varepsilon_{E M}$ due to the inhomogeneity among individual materials. Three group of samples were randomly selected to carry out experiments under given strain rates, and the results showed that the range of $\varepsilon_{E M}$ was about $0.5 \%$ to $1 \%$.

When the $\varepsilon$ is less than $\varepsilon_{E M}$, the open-circuit output voltage increases with the strain rate, but the discharge duration decreases. If the piezoelectric ceramic is regarded as a current source, the output electric displacement can be expressed as

$$
D=Q / S=\frac{\int_{0}^{t} u(t) d t}{R \pi r^{2}}
$$

where $U(t)$ is the open-circuit output voltage; $R$ is the internal resistance of the material, and $r$ is the radius of the material. Assuming $\eta=R \pi r^{2}$, then

$$
\int_{0}^{t} u(t) d t=\eta D
$$



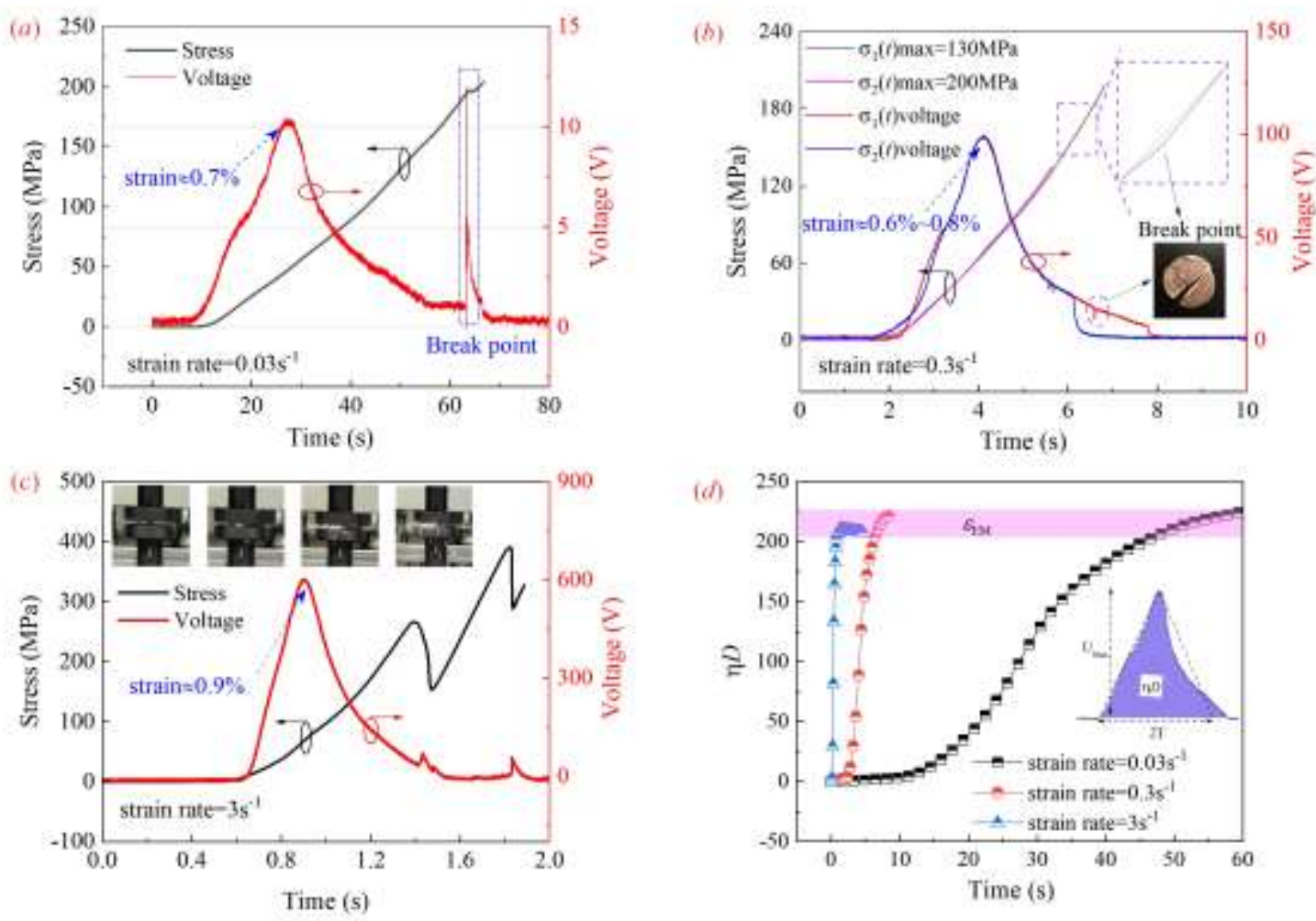

(e)

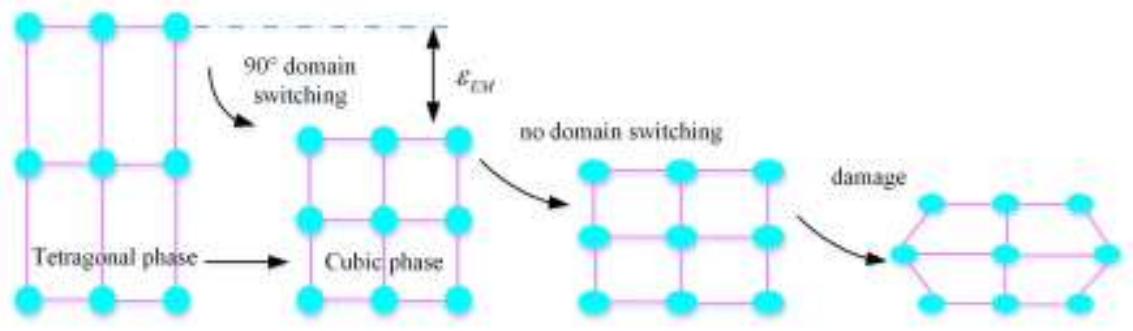

Fig.12 Open-circuit output voltage of PZT-5H under different loading rates. (a) strain rate is $0.03 \mathrm{~s}^{-1}$;

(b) strain rate is $0.3 \mathrm{~s}^{-1} ;(c)$ strain rate is $3 \mathrm{~s}^{-1} ;(d)$ output energy normalization; (e) non-continuous discharge model.

Since $\eta$ is a constant, the output charge of PZT can be measured by the integration of $U(t)$, as shown in Fig.12 (d). It can be seen that no matter how the loading rate changes, PZT has a constant output charge when the strain reaches $\varepsilon_{E M}$. If $U(t)$ is simplified as a triangle with a length of $2 T$ and a height of $U_{\max }$, then

$$
T U_{\text {max }}=\eta D
$$

Under constant strain rate loading, $T=\varepsilon_{E M} / \&$,

$$
U_{\max }=\frac{\eta D \&}{\varepsilon_{E M}}
$$

Where \&is the strain rate. Eq. (5) shows that the open-circuit output voltage is proportional to the strain rate under high-pressure stress pulse.

The physical mechanism of charge generation in PZT under stress pulse can be explained that the tetragonal ferroelectric phase changes into cubic phase under high pressure to form an electric dipole, which results in domain switching at mesoscale and 
depolarization at macroscale. As shown in Fig.12 (e), the electric dipole formed by pre-polarization deflects when PZT-5H subjected to high-voltage stress pulse, releases charge induced, and forms the potential difference between the two electrodes. When the $\varepsilon$ is larger than $\varepsilon_{E M}$, there is no more domain switching and the charge between the two electrodes leaks through the voltmeter. The failure of the material occurs when the sample is further compressed. It can be inferred that $\varepsilon_{E M}$ is related to the maximum strain in the butterfly loop of the ferroelectric material.

\section{Conclusion}

In this paper, the SHPB system and the dynamic \& static universal test machine are used to study the influence of loading frequency and circuit load on the electrical output performance of PZT-5H under high-pressure stress pulse, and the related physical mechanism is analyzed. The conclusions can be drawn as following:

(1) Under high-frequency and high-pressure stress pulse, $R_{\text {critical }}$ decreases with the loading frequency. When $R_{\text {load }}$ is less than $R_{\text {critical }}$, the output voltage is positively correlated with $R_{\text {load. }}$. Due to the ferroelectricity of PZT, the negative charge appears at the unloading stage.

(2) The full-bridge rectifier circuit can improve the energy conversion rate of the material, and the output power is related to the energy storage capacitor. With the help of a water-flow model, the electromechanical response of PZT under impact can be better understood.

(3) Under low-frequency and high-pressure stress pulse, the hoop confinement fracture strength of PZT increases with the increase of strain rate. When the $\varepsilon$ is larger than $\varepsilon_{E M}$, there is no more domain switching, furthermore the open-circuit output voltage of PZT is proportional to the strain rate when the material releases energy completely under constant strain rate loading.

\section{Acknowledgements}

This research was supported by the National Natural Science Foundation of China (Grant No. 11472178). Thanks to the research group in the Key Laboratory of Transient Physical Mechanics and Energy Conversion Materials of Liaoning Province for their support during the experiments, especially for the efforts of He Zhenhui, Liu Chang, Leng Bingyu and He Tiantian in experimental measurements.

\section{References}

[1] Hu T, Kan E. Research progress of low-dimensional ferroelectric materials[J]. Acta Physica Sinica, 2018, 67(15): 157701. http://dx.doi.org/10.7498/aps.67.20180483

[2] Gomah-Pettry J, Senda S, Marchet, et al. Sodium-bismuth titanate based lead-free ferroelectric materials[J]. Journal of the European Ceramic Society, 2004, 24(6): 1165-1169. https://doi.org/10.1016/S0955-2219(03)00473-4

[3] Kim P, Doss N M, Tillotson J P, et al. High energy density nanocomposites based on 
surface-modified $\mathrm{BaTiO}_{3}$ and a ferroelectric polymer[J]. ACS Nano, 2009, 3(9): 2581-2592. https://doi.org/10.1021/nn9006412

[4] Yu K, Niu Y, Zhou Y, et al. Nanocomposites of surface-modified $\mathrm{BaTiO}_{3}$ nanoparticles filled ferroelectric polymer with enhanced energy density[J]. Journal of the American Ceramic Society, 2013, 96(8): 2519-2524. https://doi.org/10.1111/jace.12338

[5] Park K, Son J H, Hwang G, et al. Highly-efficient, flexible piezoelectric PZT thin film nanogenerator on plastic substrates[J]. Advanced Materials, 2014, 26(16): 2514-2520. https://doi.org/10.1002/adma.201305659

[6] Qi Y, Kim J, Nguyen T D, Enhanced piezoelectricity and stretchability in energy harvesting devices fabricated from buckled PZT ribbons[J]. Nano Letter, 2011, 11(3): 1331-1336. https://doi.org/10.1021/nl104412b

[7] Theissmann R, Schmitt L A, Kling J, et al. Nanodomains in morphotropic lead zirconate titanate ceramics: On the origin of the strong piezoelectric effect[J]. Journal of Applied Physics, 2007, 102: 024111. https://doi.org/10.1063/1.2753569

[8] Zou D, Liu S, Zhang C, et al. Flexible and translucent PZT films enhanced by the compositionally graded heterostructure for human body monitoring $[\mathrm{J}]$. Nano Energy, 2021, 85: 105984. https://doi.org/10.1016/j.nanoen.2021.105984

[9] Eyraud L, Guiffard B, Audigier D, et al., Electron transfer mechanism in PZT ceramics - application to squeeze ignition[J]. Ferroelectrics, 2008, 366 (1): 37-44. http://dx.doi.org/10.1080/00150190802363108

[10] Wang R, Tang E, Yang G, et al. Experimental simulation of self-powered overload igniter based on Lead Zirconate Titanate[J]. Sensors and Actuators A: Physical, 2020, 314: 112222. https://doi.org/10.1016/j.sna.2020.112222

[11] Wang G, Li Y, Cui H, et al. Acceleration self-compensation mechanism and experimental research on shock wave piezoelectric pressure sensor[J]. Mechanical $\begin{array}{lllll}\text { Systems } & \text { and } & \text { Signal } & \text { Processing, 2021, 105: }\end{array}$ https://doi.org/10.1016/j.ymssp.2020.107303

[12] Wang R, Tang E, Yang G, et al. Construction of PZT-5H mechano-electric model based on strain rate dependence and its numerical simulation in overload igniter application[J]. Mechanics of Materials, 2021, 157: 103837. https://doi.org/10.1016/j.mechmat.2021.103837

[13] Jiang Z, Gao G, Wang X, et al. Strain rate and porosity effect on mechanical characteristics and depolarization of porous poled PZT95/5 ceramics[J]. Materials, 2020, 13(21): 4730. https://doi.org/10.3390/ma13214730

[14] Kumar A, Vishal S, Kumar R, et al. Electromagnetic radiation detection in cement-mortar/lead zirconate titanate composites using drop-weight impact technique[J]. Construction and Building Materials, 2021, 273(1): 122022. 
https://doi.org/10.1016/j.conbuildmat.2020.122022

[15] Jiang Z, Gao G, Xiong X, et al. Mechanical response and deformation mechanisms of porous PZT95/5 ceramics under shock-wave compression[J]. Journal of the European $\begin{array}{llll}\text { Ceramic } & \text { Society, } & \text { 2021, } & \text { 41(2): }\end{array}$ https://doi.org/10.1016/j.jeurceramsoc.2020.09.051

[16] Xiong Z, Liu G, Nie H, et al. Shock-driven depolarization behaviors and electrical output in $\mathrm{BiAlO}_{3}$-doped $\mathrm{Bi}_{0.5} \mathrm{Na}_{0.5} \mathrm{TiO}_{3}$ ferroelectric ceramics[J]. 2021, 104(2): 1169-1177. https://doi.org/10.1111/jace.17531

[17] Fritz I J, Keck J D. Pressure-temperature phase diagrams for several modified lead zirconate ceramics[J]. Journal of Physics and Chemistry of Solids, 1978, 39(11): 1163-1167. https://doi.org/10.1016/0022-3697(78)90090-2

[18] Ujma Z, Hańderek J. Peculiarities of the pyroelectric effect and of the dielectric properties in $\mathrm{Bi}$-doped $\mathrm{Pb}\left(\mathrm{Zr}_{0.95} \mathrm{Ti}_{0.05}\right) \mathrm{O}_{3}$ ceramics[J]. Journal of the European Ceramic Society, 2003, 23(2): 203-212. https://doi.org/10.1016/S0955-2219(02)00180-2

[19] Cordero F, Buixaderas E, Galassi C. Damage from coexistence of ferroelectric and antiferroelectric domains and clustering of $\mathrm{O}$ vacancies in PZT: an elastic and raman study[J]. Materials, 2019, 12(6): 957. https://doi.org/10.3390/ma12060957

[20] Tang E, Li Y, Wang R, et al. The Propagation of stress wave in the PZT-5H composite target and the influence of load resistance on the electrical output under the strong shock loading[J]. IEEE Transactions on Plasma Science, 2018, 46(2): 415-421. https://doi.org/10.1109/TPS.2017.2783887

[21] Su Y, Li S, Huan Y, et al. The universal and easy-to-use standard of voltage measurement for quantifying the performance of piezoelectric devices[J]. Extreme Mechanics. Letters, 2017, 15: 10-16. https://doi.org/10.1016/j.eml.2017.03.002

[22] Tang E, Wang L, Wang R, et al. Relationships between shock stress and electrical output characteristics for PZT-5H under high-velocity impact loading[J]. Mechanics of Advanced Materials and Structures, 2019, $27 \quad$ (24): 2035-2042. https://doi.org/10.1080/15376494.2018.1539197

[23] Selvan K, Mohamed S. Micro-scale energy harvesting devices: Review of methodological performances in the last decade[J]. Renewable and Sustainable Energy Reviews, 2016, 54: 1035-1047. https://doi.org/10.1016/j.rser.2015.10.046

[24] Safaei M, Sodano H A, Anton S R. A review of energy harvesting using piezoelectric materials: state-of-the-art a decade later (2008-2018)[J]. Smart Materials and Structures, 2019, 28(11): 113001. https://doi.org/10.1088/1361-665X/ab36e4

[25] Butt Z, Anjum Z, Sultan A, et al. Investigation of electrical properties \& mechanical quality factor of piezoelectric material (PZT-4A)[J]. Journal of Electrical $\begin{array}{lllll}\text { Engineering } \quad \& \quad \text { Technology, } & \text { 2017, } & \text { 12(2): }\end{array}$ https://doi.org/10.5370/JEET.2017.12.2.846 
[26] Wang G, Li P, Wen Y, et al. Self-Powered ultra-low-power low-threshold synchronous circuit for weak piezoelectric energy harvesting[J]. Sensors and Actuators A: Physical, 2021, 322: 112632. https://doi.org/10.1016/j.sna.2021.112632

[27] Li H, Bowen C R, Yang Y. Scavenging energy sources using ferroelectric materials[J]. Advanced Functional Materials, 2021, 2100905. https://doi.org/10.1002/adfm.202100905.

[28] Zhou N, Gao S, Li R, et al. Transient output performance of symmetrical V-shaped micro-piezoelectric energy harvester by using PZT-5H[J]. Microsystem Technologies, 2021, 27: 779-787. https://doi.org/10.1007/s00542-020-04994-4

[29] Xiao Z, Yang T, Dong Y, et al. Energy harvester array using piezoelectric circular diaphragm for broadband vibration[J]. Applied Physics Letters, 2014, 104: 223-904. http://dx.doi.org/10.1063/1.4878537

[30] Jiang Z, Gao G, Xiong X, et al. Mechanical response and deformation mechanisms of porous PZT95/5 ceramics under shock-wave compression[J]. Journal of the European $\begin{array}{llll}\text { Ceramic } & \text { Society, } & \text { 2020, } & \text { 41(2): }\end{array}$ https://doi.org/10.1016/j.jeurceramsoc.2020.09.051

[31] Wang R, Tang E, Yang G, et al. Experimental research on dynamic response of PZT-5H under impact load[J]. Ceramics International, 2020, 46(3): 2868-2876. https://doi.org/10.1016/j.ceramint.2019.09.280

[32] Wang R, Tang E, Yang G, et al. Electromechanical behaviors of soft and hard PZTs under different compressive stress pulses[J]. Mechanics of Materials, 2020, 149: 103544. https://doi.org/10.1016/j.mechmat.2020.103544 

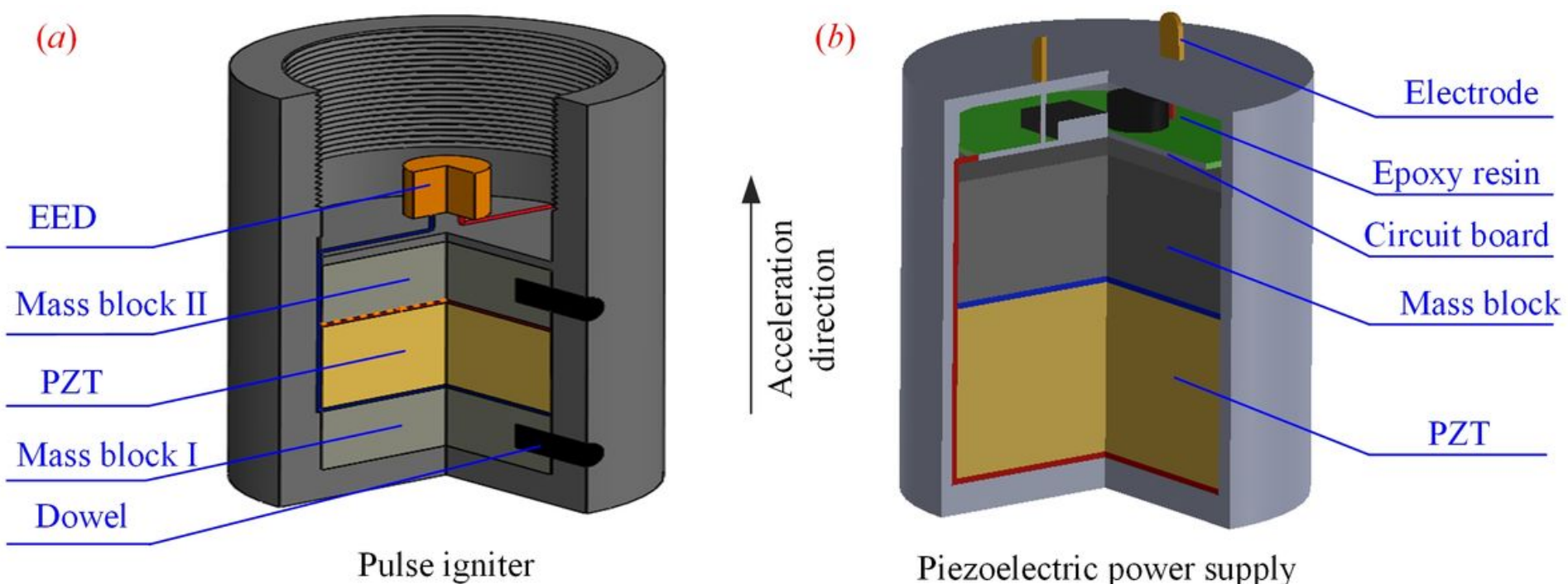

Piezoelectric power supply

\section{Figure 1}

Typical piezoelectric devices for ammunition. (a) pulse igniter; (b) piezoelectric power supply.

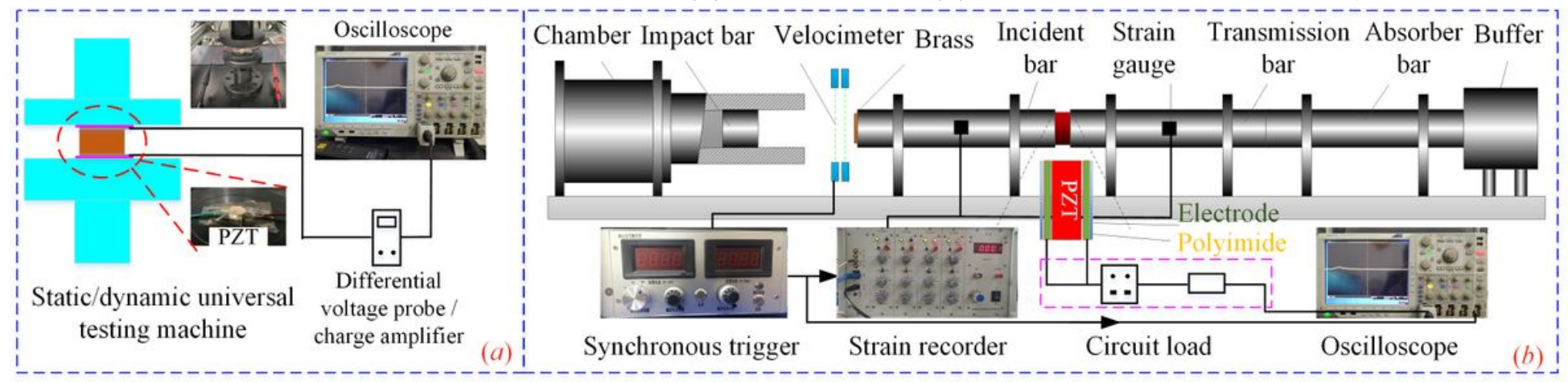

Figure 2

Experimental loading and testing system. (a) low-frequency stress pulse loading; (b) high-frequency stress pulse loading. 

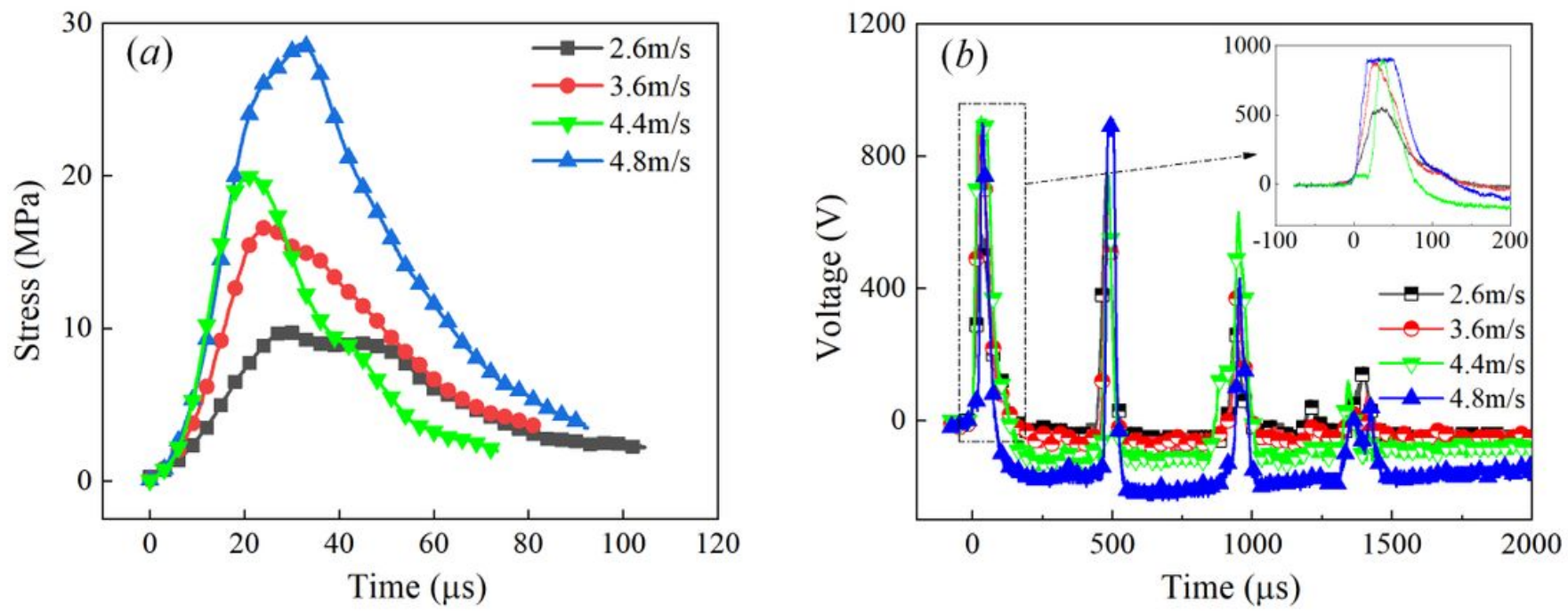

\section{Figure 3}

The output voltage of PZT-5H under different impact speeds (load resistance=1M $\Omega$ ). (a) stress time history; (b) voltage time history. 


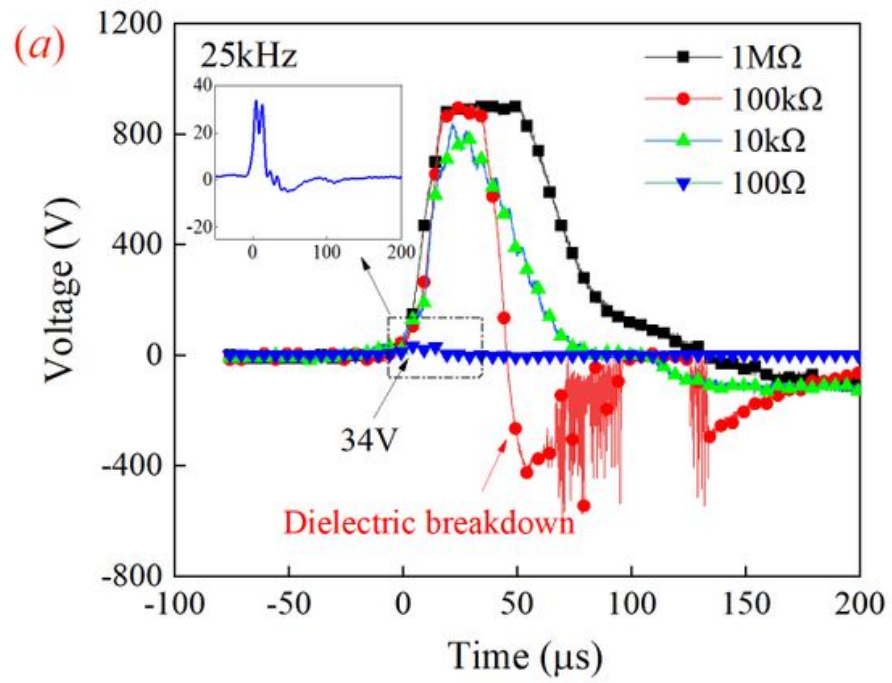

(b)
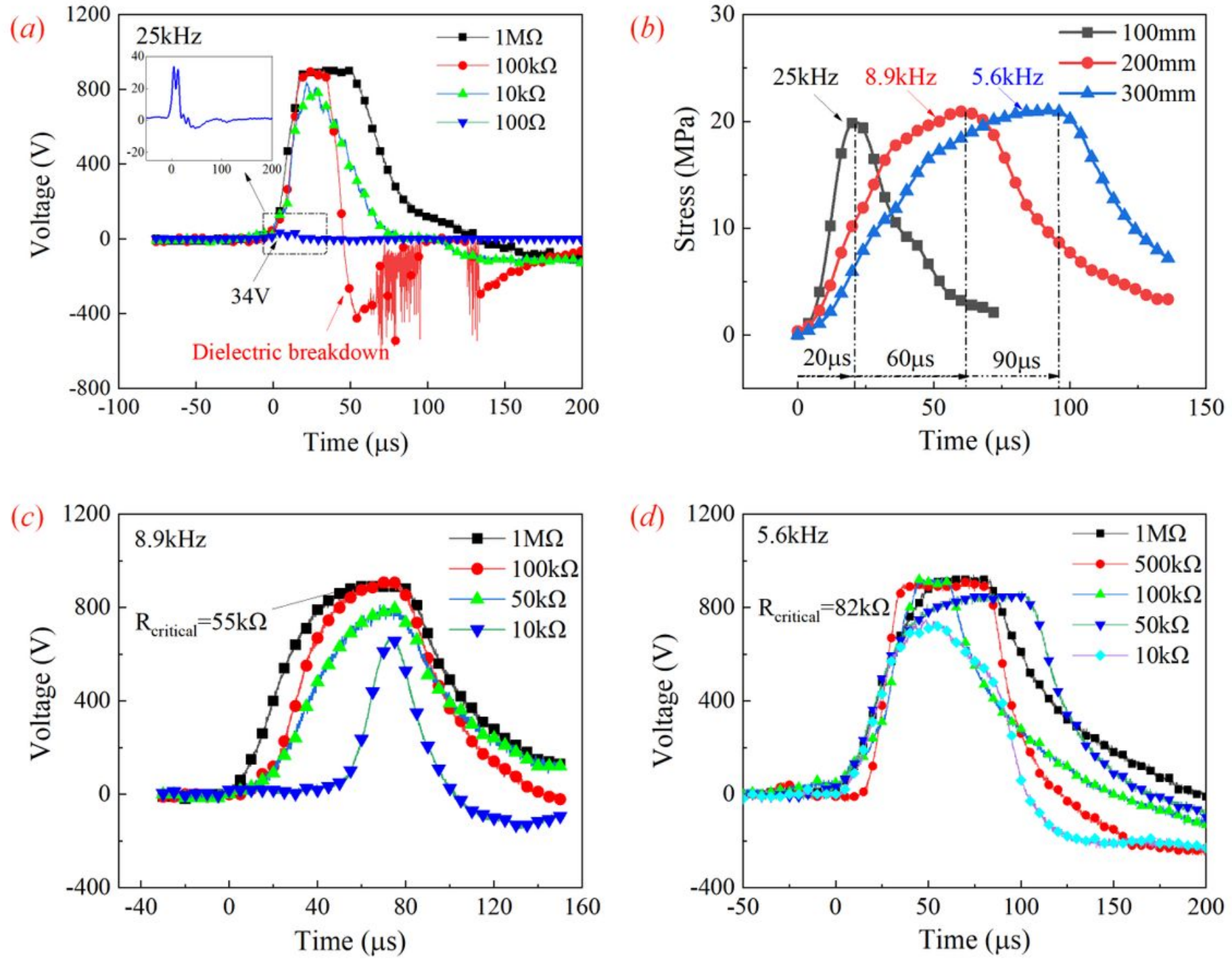

Figure 4

The influence of loading frequency and load resistance on output voltage under high-frequency stress pulse $(4.8 \mathrm{~m} / \mathrm{s})$. (a) length of the impact bar is $100 \mathrm{~mm}$; (b) stress time history curves produced by different impact bars; (c) length of the impact bar is $200 \mathrm{~mm}$; (d) length of the impact bar is $300 \mathrm{~mm}$ 


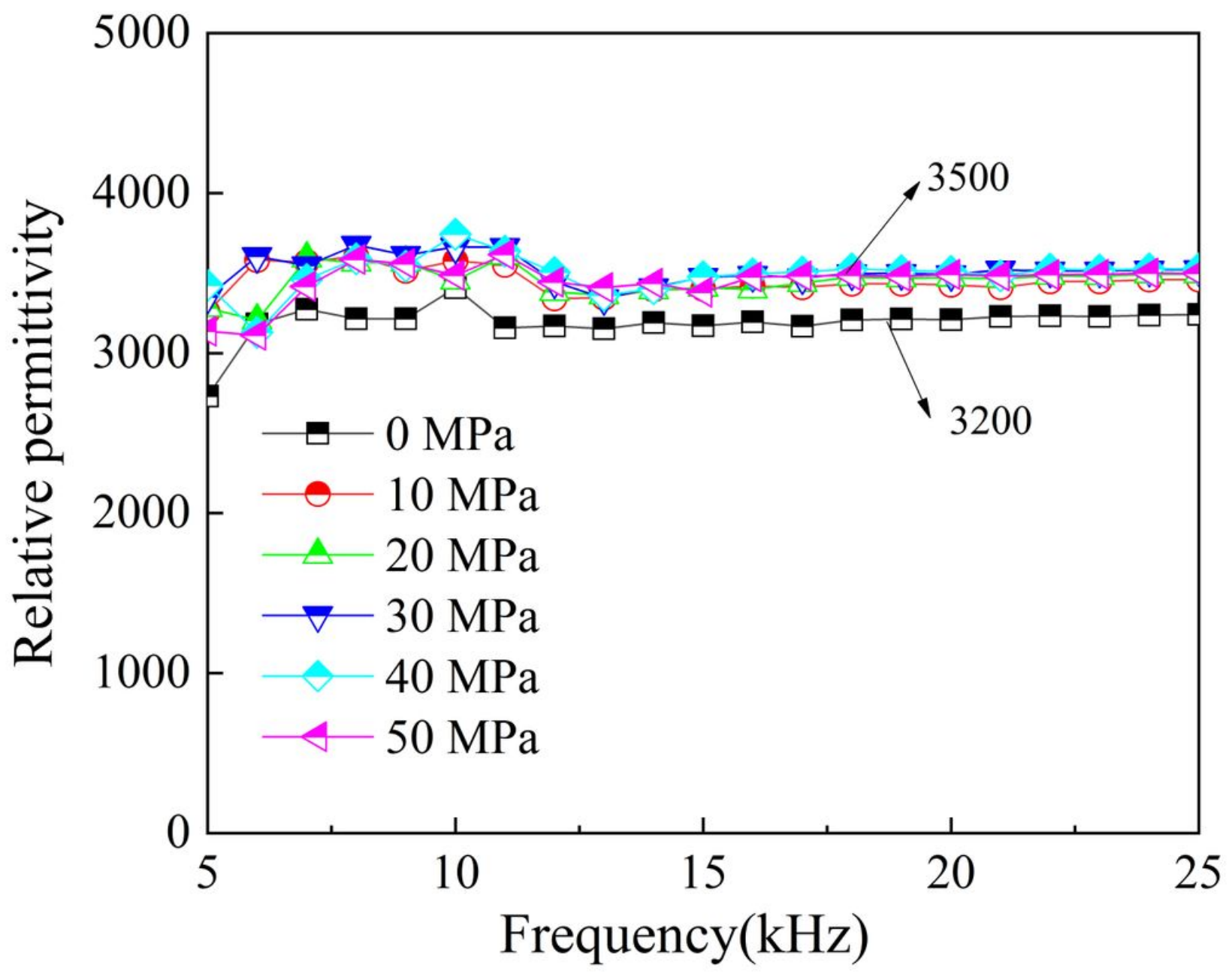

Figure 5

Dielectric spectrum of PZT under different stress 

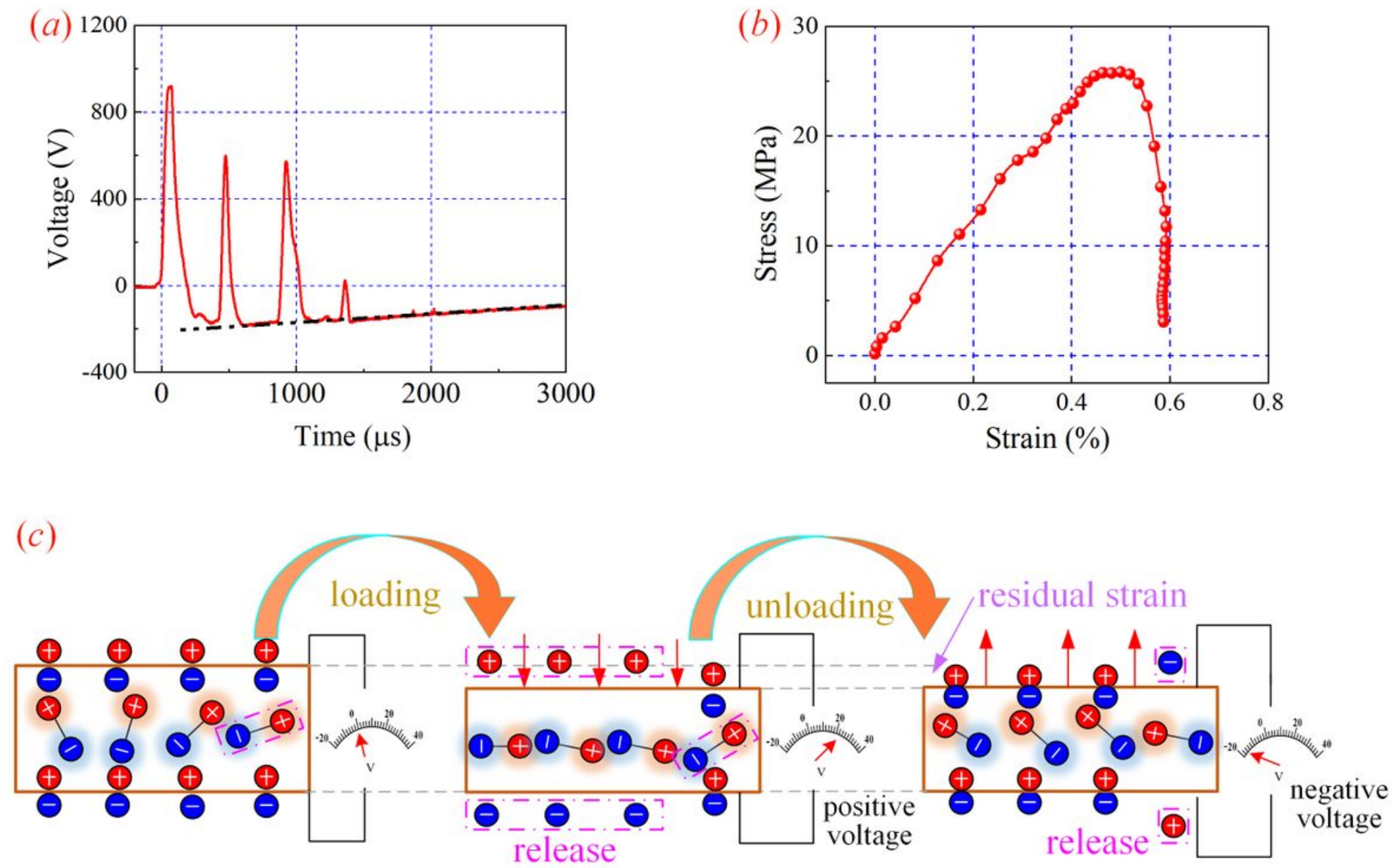

Figure 6

Typical open-circuit voltage of PZT under impact. (a) output voltage with a negative value; (b) residual strain after stress unloading; (c) open-circuit discharge model. 


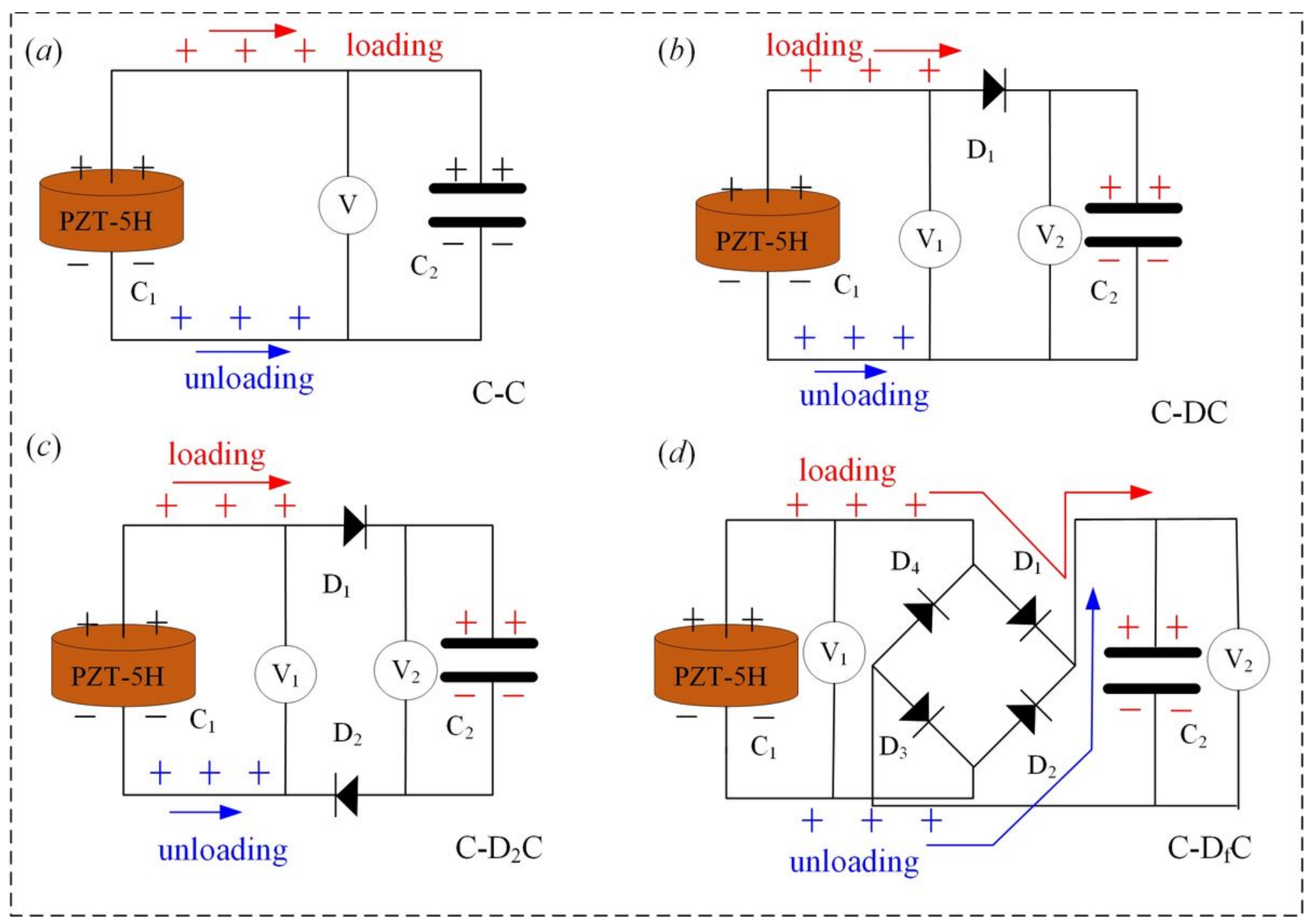

Figure 7

Four types of energy storage circuits. (a) load capacitance only (C-C); (b) load capacitance and connect a diode in series with the anode (C-DC); (c) load capacitance and connect two diodes in positive and negative poles series in opposite directions (C-D2C); (d) load capacitance and full bridge rectifier module (C-DfC). 

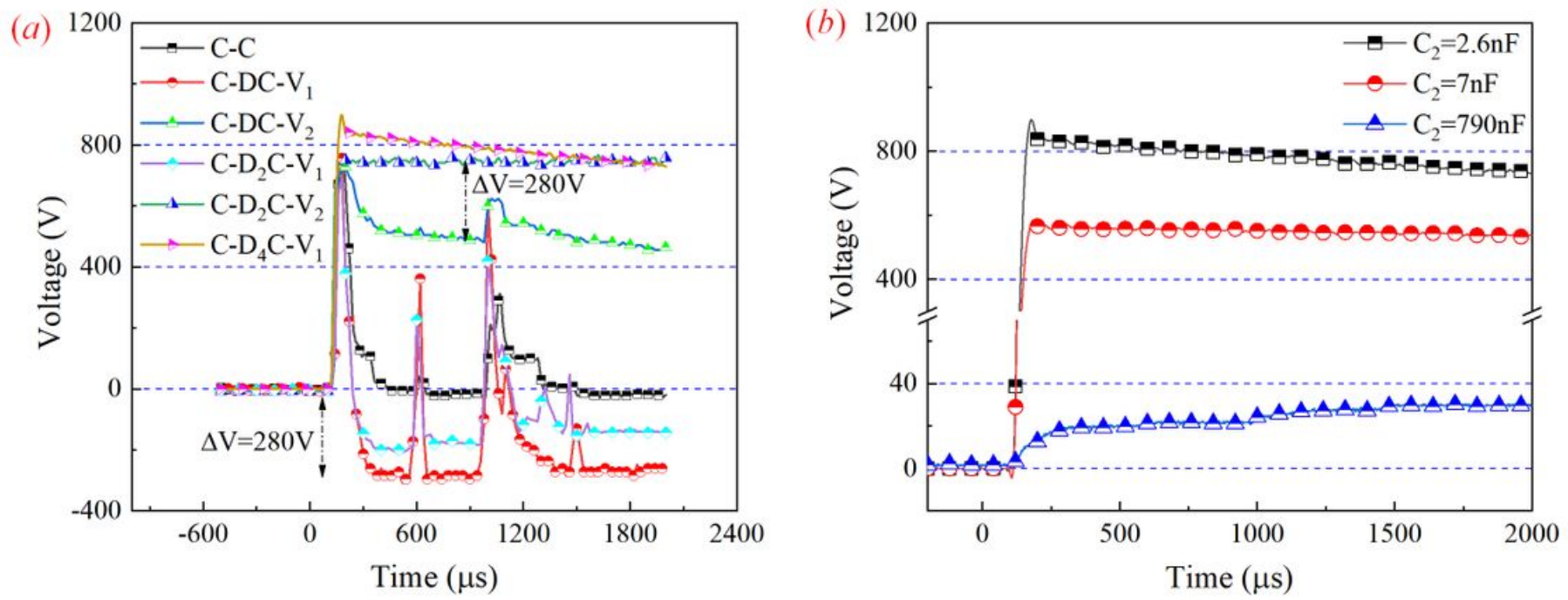

\section{Figure 8}

Output voltage time history curves. (a) output voltage of four circuits; (b) energy storage voltage of C-DfC under different capacitor values of $\mathrm{C} 2$.
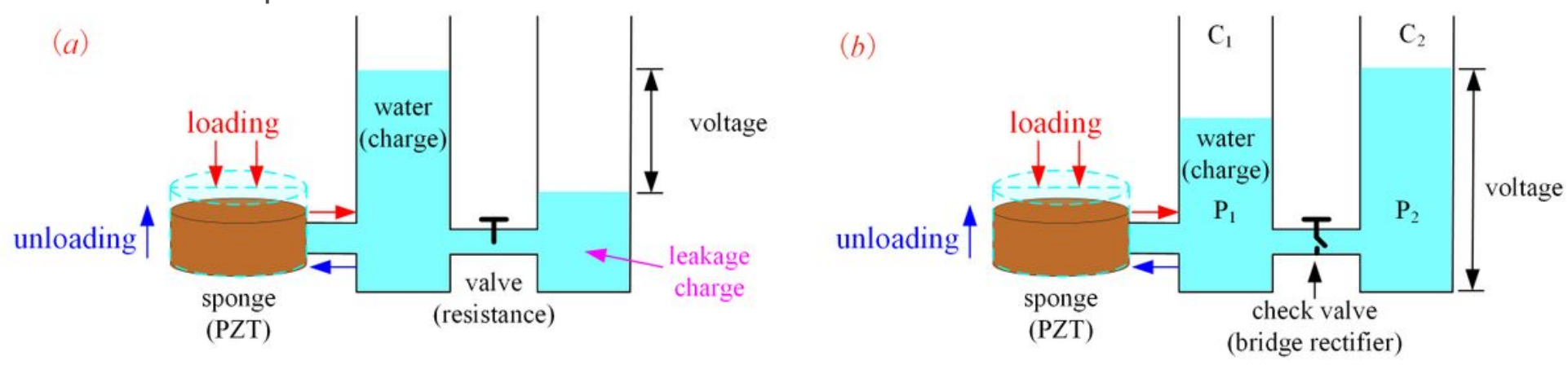

\section{Figure 9}

Electromechanical response equivalent model of piezoelectric materials. (a) load resistance; (b) load capacitance. 

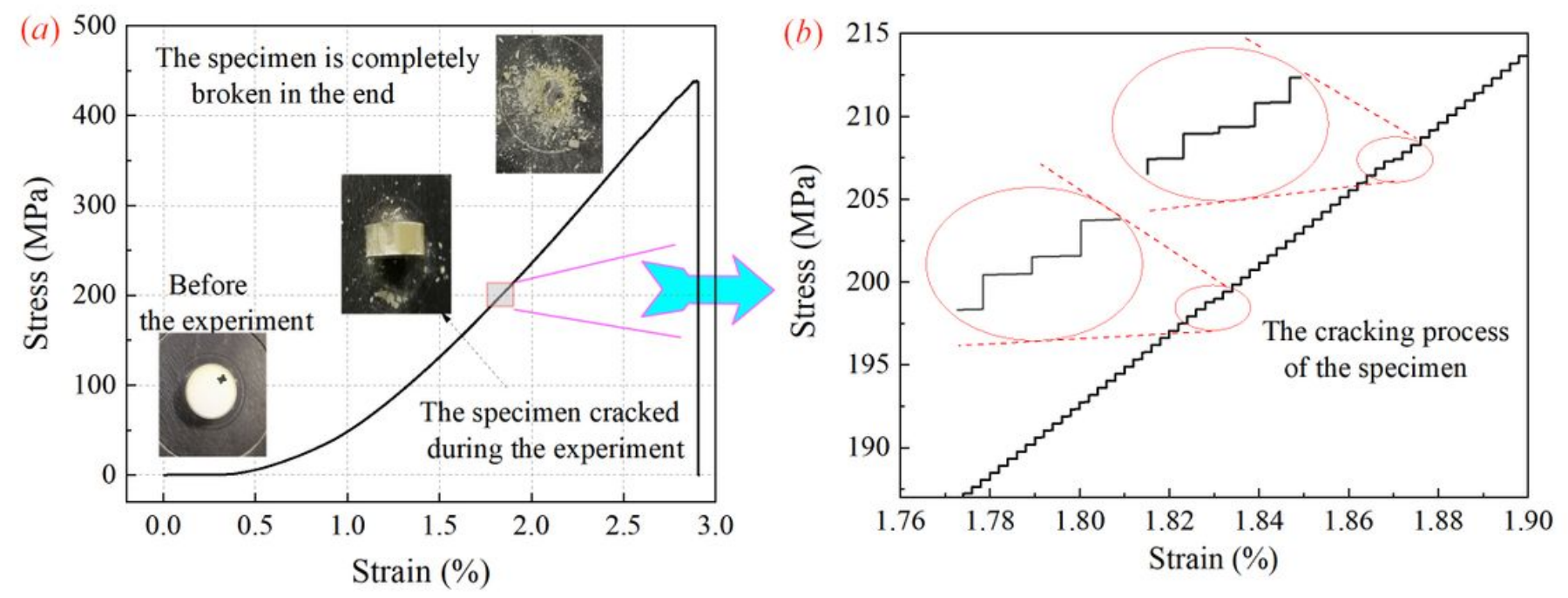

Figure 10

Quasi-static stress-strain curve of PZT-5H (unconstrained). (a) complete curve; (b) local enlarge.

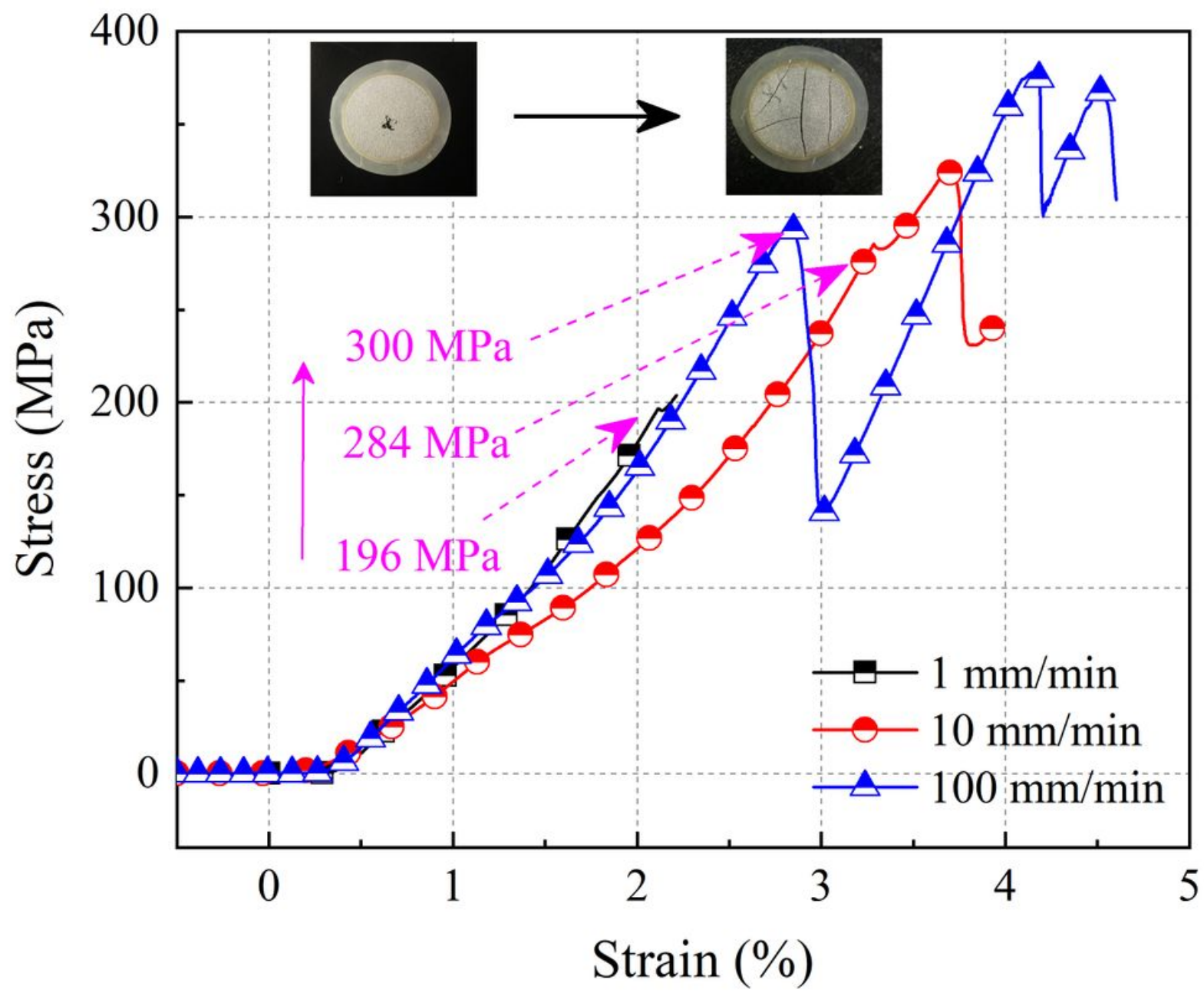


Figure 11

Stress-strain curve of PZT-5H under different strain rates (surrounding constraints)
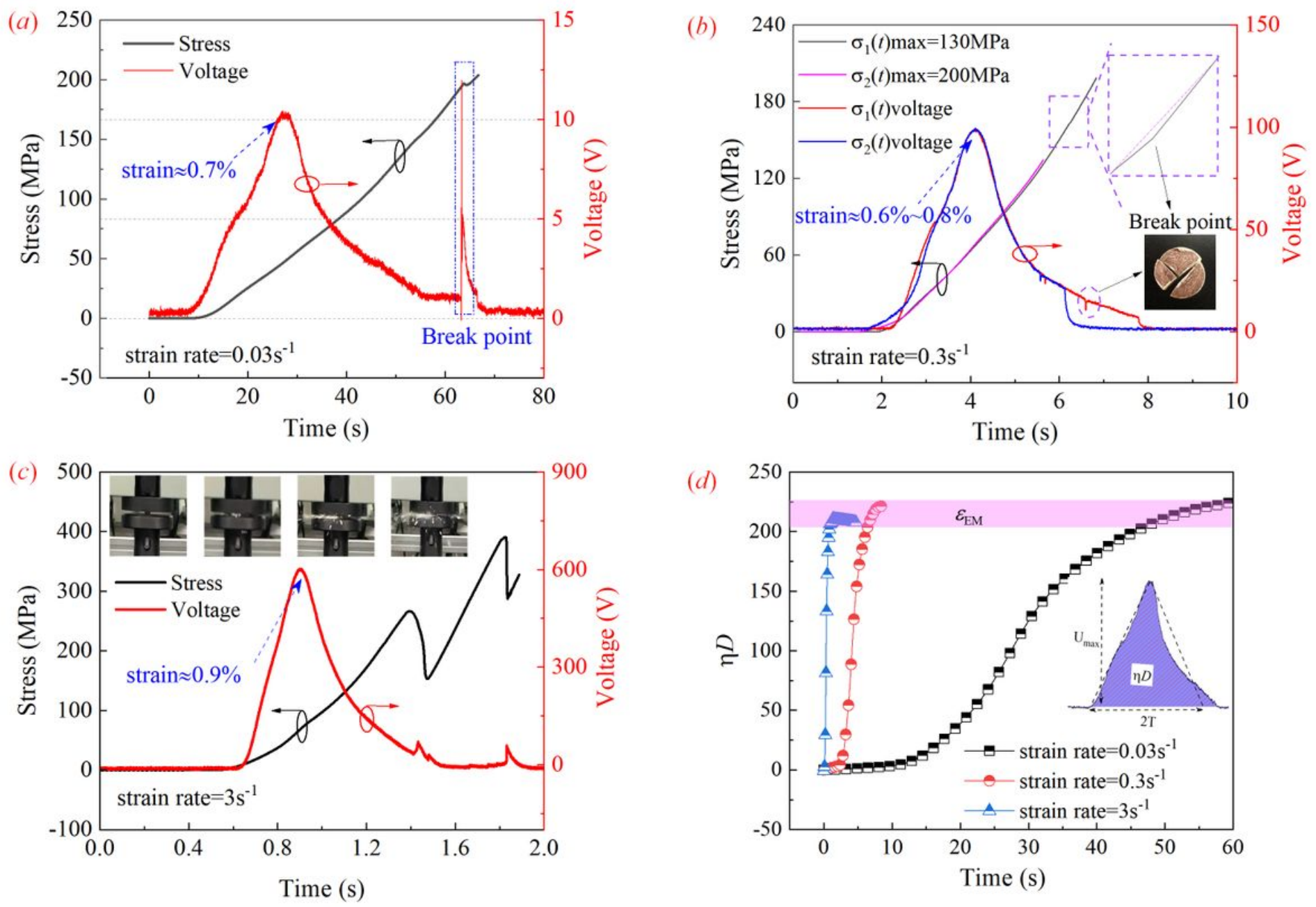

(e)

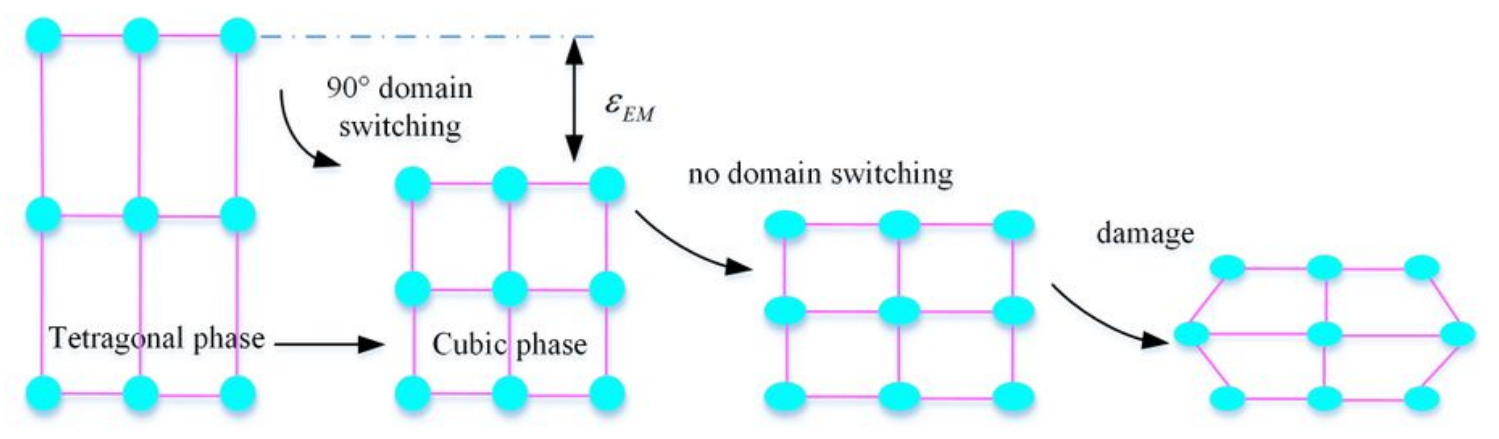

\section{Figure 12}

Open-circuit output voltage of PZT-5H under different loading rates. (a) strain rate is $0.03 \mathrm{~s}-1$; (b) strain rate is $0.3 \mathrm{~s}-1$; (c) strain rate is $3 \mathrm{~s}-1$; (d) output energy normalization; (e) non-continuous discharge model. 